OPEN ACCESS

Edited by:

Colin T. Dourish,

P1vital Limited, United Kingdom

Reviewed by:

Michael James Winkelman, Arizona State University, United States Mathieu Seynaeve, King's College London, United Kingdom

*Correspondence: Rita Kočárová kocarova.rita@gmail.com

Specialty section: This article was submitted to Psychopharmacology, a section of the journal Frontiers in Psychiatry

Received: 08 February 2021 Accepted: 04 June 2021 Published: 19 July 2021

Citation: Kočárová $R$, Horáček J and Carhart-Harris R (2021) Does Psychedelic Therapy Have a

Transdiagnostic Action and

Prophylactic Potential?

Front. Psychiatry 12:661233. doi: 10.3389/fpsyt.2021.661233

\section{Does Psychedelic Therapy Have a Transdiagnostic Action and Prophylactic Potential?}

\author{
Rita Kočárová ${ }^{1,2,3 *}$, Jiři Horáček ${ }^{4,5}$ and Robin Carhart-Harris ${ }^{6}$ \\ ${ }^{1}$ Department of Translational Neuroscience, National Institute of Mental Health, Klecany, Czechia, ${ }^{2}$ Department of \\ Psychology, Faculty of Arts, Charles University, Prague, Czechia, ${ }^{3}$ Beyond Psychedelics, Prague, Czechia, ${ }^{4}$ Department of \\ Applied Neuroscience and Neuroimaging, National Institute of Mental Health, Klecany, Czechia, ${ }^{5}$ Third Faculty of Medicine, \\ Charles University, Prague, Czechia, ${ }^{6}$ Centre for Psychedelic Research, Imperial College London, London, United Kingdom
}

Addressing global mental health is a major 21st-century challenge. Current treatments have recognized limitations; in this context, new ones that are prophylactic and effective across diagnostic boundaries would represent a major advance. The view that there exists a core of transdiagnostic overlap between psychiatric disorders has re-emerged in recent years, and evidence that psychedelic therapy holds promise for a range of psychiatric disorders supports the position that it may be transdiagnostically effective. Here, we propose that psychedelic therapy's core, transdiagnostically relevant action lies in its ability to increase neuronal and mental plasticity, thus enhancing the potential for change, which we consider to be a key to its therapeutic benefits. Moreover, we suggest that enhanced plasticity via psychedelics, combined with a psychotherapeutic approach, can aid healthy adaptability and resilience, which are protective factors for long-term well-being. We present candidate neurological and psychological markers of this plasticity and link them with a predictive processing model of the action of psychedelics. We propose that a model of psychedelic-induced plasticity combined with an adequate therapeutic context has prophylactic and transdiagnostic potential, implying that it could have a broad, positive impact on public health.

Keywords: psychedelics, hallucinogens, psilocybin, psychological flexibility, plasticity, prevention, transdiagnostic, well-being

\section{INTRODUCTION}

To provide the background for our central thesis-that psychedelic therapy possesses a transdiagnostic and prophylactic potential-we first discuss current mental healthcare challenges before introducing a potential solution: the identification of a transdiagnostic treatment target that can aid prophylaxis or the long-term protection of mental health. We argue that psychedelic therapy has the potential to meet these two criteria. Key to our synthesis is evidence that psychedelics promote brain and mind "plasticity," where plasticity can be defined in its purest sense as the quality of being easily shaped or molded (1). In the present paper, we use plasticity in this fundamental sense in relation to both the brain and mind (i.e., psychological phenomena), where enhanced plasticity of either phenomenon implies an enhanced capacity for change. In its purest, as well as in its classic biological sense, plasticity is closely related to "adaptability," as the property of being easily shaped or molded naturally interfaces with conditional forces or factors that could shape or mold the plastic phenomenon in a particular way. 
In this paper, we aim to integrate the property of enhanced brain and mind plasticity via psychedelics with a predictive processing framework that is intended to apply equally well on psychological and neurobiological levels. This model constitutes an interdisciplinary approach to the mechanism of action of psychedelic therapy. Importantly, we explain how the model implies the prophylactic potential of psychedelic therapy-with implications for efforts to aid the development of psychedelic therapy into a regulated intervention for the recovery, promotion, and protection of psychological wellness.

Consistent with recent evidence supportive of these bold claims, we elect not to treat psychological health as a mechanistically discrete entity separate from pathology (2). In our view, reinforced "problematic" habits of brain and mind are universally relevant maladaptive processes (3). Put very simply, we argue that increased mental and neuronal plasticity, in combination with ideally supportive environmental contexts, can serve to promote psychological well-being on state and trait levels.

Mental health disorders are currently among the leading causes of disability worldwide. At least 300 million people suffer from depression, and close to 800,000 suicides are committed every year, with most linked to a mental health condition (4). There are thus, enormous human, social, and economic costs linked to mental illness (5), warranting that it be regarded as a major priority area.

Considering the magnitude of the burden of mental illness, its increasing global prevalence, and growing costs of healthcare (5), purely reactive interventions are unlikely to have sufficient impact (6). Moreover, there is a dearth of truly novel and effective new psychiatric drugs (7). Most current drugs have a lag in their therapeutic onset, possess a range of side effects (8), and show a modest efficacy relative to placebo $(9-11)$; $~ 20 \%$ of patients are resistant to any of the presently licensed treatment options $(10,12)$. Moreover, pure pharmacotherapy, while convenient for "industrial" healthcare, may not have the correct action to target etiological causes in a manner that can serve long-term well-being (3).

While patients generally prefer talking therapies (13), questions remain over access, cost, speed of therapeutic action, and efficacy-particularly for severe cases (14). Thus, it is widely recognized that current treatments have limitations and that therapeutic breakthroughs are needed (5).

The World Health Organization (WHO) recognizes the potential value of proactive or preventative strategies for tackling the global burden of mental illness (5). Compared with preventative strategies in other domains of healthcare, progress in the prevention of mental illness has been poor (15). This may be due in part to industrial forces, including an excessive reliance on "myopic" (e.g., drug alone) interventions that may fail to target key underlying generative sources of illness (15). Consistent with this, a shift in focus in mental healthcare and research to strategies that promote wellness, and the capacity to address and cope adaptively with adversities seem justified and timely (15). The promotion of health and prevention of illness are interrelated in many respects (15) - a position backed by recent evidence of the continuous relationship between mental health and illness (2).

As the rapid discovery of effective vaccines for COVID19 has demonstrated, an understanding of the etiology of a disease dramatically affects our ability to find effective treatments for it. In the context of mental illness, our incomplete understanding of the etiology of psychological suffering may be a major reason why our current treatments are not sufficiently effective. Regarding etiology, there is substantial evidence for an association between acute and chronic adversity and the development of many of the most prevalent and disabling psychiatric disorders $(5,16)$. Traumatic experiences during childhood are a well-known risk factor for various psychiatric disorders in adulthood (17). Decades of evidence has tended to suggest that the most prevalent psychiatric disorders (such as depression and anxiety disorders) feature a substantial environmental component in their etiology (3), albeit with a non-negligible but largely transdiagnostically shared genetic component (18) that seems to confer "vulnerability" or possibly even just "sensitivity to environment" - with direct and indirect links to plasticity $(18,19)$.

Thus, a large body of evidence implies the existence of individual differences in vulnerability to mental illness after adverse experiences (20). This differential sensitivity may depend on polygenic $(18,21)$, neurobiological $(22,23)$, environmental (24), psychological (25), and social factors (20). A composite vulnerability factor referred to as "resilience" has been the focus of research on preventative strategies in mental healthcare research (6), but is there a related and perhaps even more fundamental and tangible treatment target?

Two main strategies have been identified for the prevention of the development of mental health disorders and promotion of mental health: (1) the identification and potential mitigation of psychological, biological, community, economic, and environmental risk factors and (2) the strengthening of protective factors (26). We argue that psychedelic therapy can serve the latter factor in particular, by promoting a generalized mental and neural plasticity in combination with an ideally nurturing or supportive therapeutic context. Again, we adopt a standard dictionary definition of plasticity as the ability to change or be shaped by surrounding conditions (1).

Borrowing from genetic science (27), we also argue that a broad range of psychopathology can be conceived of as a maladaptive "canalization" of thought and behavior. Canalization can be defined as the maintenance of a trajectory (e.g., a style of thinking, feeling, relating, and/or behavior) that is resistant to change. Thus, in a sense, canalization is the inverse of plasticity. It is tempting to infer that canalized thought and behavior are an adaptive, defensive response to adversity that may thus, perhaps, paradoxically confer some (context dependent) evolutionary advantages (28). However, where such canalization creates maladaptive phenotypes-i.e., maladaptive in the context of a demanding modern western society-the logical way to treat it is to intervene to increase plasticity. Psychedelic therapy combines a plasticity-enhancing drug action with nurturing conditions-for the purpose of fostering a reset or recalibration of "maladaptive" habits of mind or behavior (29). Put most 
simply, we propose that the core therapeutic value of psychedelic therapy lies in its ability to open a window for healthy change.

There is a growing view that markers of mental health and treatment targets may be transdiagnostically relevant $(30,31)$. The transdiagnostic approach is characterized by identifying and targeting modifiable factors that traverse standard diagnostic categories $(30,31)$. This view is well-supported by the strong comorbidity of mental health disorders $(32,33)$ and the shared polygenic overlap between them (18).

A related perspective has inspired the Research Domain Criteria (RDoc) initiative in the USA, which places greater emphasis on pathologically relevant mechanisms rather than diagnostic categories, and has attracted major funding, if (as yet) limited breakthroughs (34). A similar direction is being taken by process-based psychotherapies, where mediators and moderators of mental illness and wellness are being explored $(35,36)$. If sufficient supportive evidence is gathered for either approach, it could have a far-reaching impact on treatment decisions as well as interdisciplinary bridging between different treatment models, orientations, and settings (35).

It would be fair to recognize psychoanalytic psychology here, as it has long recognized the existence of transdiagnostic overlap or commonalities between difference symptom-level expressions of psychological suffering, e.g., through the recognition of defense mechanisms (37). A greater alliance between psychoanalytic theory and practice and psychedelic therapy and science could be particularly fruitful going forward.

\section{MENTAL HEALTH-PROMOTING AND HEALTH-MAINTAINING EFFECT OF PSYCHEDELIC THERAPY}

Classic psychedelic (mind-manifesting) substances such as psilocybin (found in so-called "magic mushrooms"), dimethyltryptamine (DMT) (e.g., a key psychedelic ingredient in ayahuasca, a traditional psychedelic brew used in areas of South America), and lysergic acid diethylamide (LSD) have recently shown promise in the treatment of a variety of mental health disorders, including addiction $(38,39)$, obsessive compulsive disorder (40), depression (41-44), and existential distress in patients with life-threatening disease (45-48). Several ongoing clinical trials are exploring these and additional indications (49). There is also naturalistic and historical evidence supporting psychedelic therapy for functional neurological disorders (50), eating disorders $(51,52)$, psychosomatic disorders $(53,54)$, posttraumatic stress disorder (PTSD) (55-57), and perhaps even personality disorders $(54,58-61)$. This non-exhaustive list serves to highlight the potential transdiagnostic appeal of psychedelic therapy-implying that it may be able to address a core common denominator of mental health (see Figure 1). We propose here that this core component is a defensive canalization of thought and/or behavior vs. combining the plasticity promoting effects of psychedelics with their psychotherapeutic delivery in "psychedelic therapy" $(28,62)$.

Besides the treatment of mental health disorders, there is growing epidemiological evidence that psychedelic therapy can have positive effects on mental health in broader populations. The analysis of a representative sample of over 100,000 people in the USA showed that lifetime prevalence of psychedelic use was associated with a lower rate of past-year inpatient psychiatric treatment, prescription of psychotropic medication, and serious psychological distress $(63,64)$, as well as suicidal thinking, planning, and attempts (65). Psychedelic use was also associated with a lower rate of suicidal thoughts in a group of people with a history of childhood depressive episodes (63). Reduced rates of suicidality have now been shown in numerous naturalistic, observational studies involving a variety of classic psychedelics (66-68) as well as in controlled research with psilocybin (43, 44, 69) and ayahuasca for depression (70). One notable recent trial showed superior reductions in suicidality with psilocybin therapy vs. a 6-week treatment with a conventional antidepressant, albeit precorrection for multiple comparisons (44).

Naturalistic research into peyote (71) and ayahuasca (72) "users" revealed a better mental health profile in this population than in matched controls. A recent review of clinical trials and epidemiological studies ( $N=77$ eligible studies with 9,876 participants) documented that the use of psychedelics in various settings and populations was associated with aggregate improvements in a variety of indices of mental health (73). Other psychological changes linked to psychedelic use include prosocial attitudes and behavior (74), increased nature-relatedness $(75,76)$, and increases in the personality traits "self-transcendence" and "openness to experience" $(77,78)$. These ancillary domains are interesting and relevant to the topic of current paper; however, due to considerations of article length, we will focus mostly on mental health outcomes, albeit with a brief discussion of trait openness and creativity.

Taken together, the above-listed findings support the central hypothesis of this paper that psychedelic therapy can have transdiagnostically relevant, mental health-promoting effects. This proposition would be more compelling however, if plausible mechanisms were found that can account for these properties (22). We propose that the combination of plasticityenhancing effects with a positive, supportive therapeutic context is conducive to psychological wellness across diagnostic boundaries, including one that would differentiate mentally healthy and unwell populations.

Mindful of projecting panacea-like properties into psychedelic therapy, we draw a specific line at mental illnesses with a clear organic etiology. We also recognize that there is a dearth of evidence to support the potential of psychedelic therapy to treat psychiatric disorders with a strong genetic contribution such as in the psychotic disorders. It has also long been suspected that psychedelic therapy may pose an elevated risk for iatrogenesis in individuals exhibiting at-risk factors for psychosis.

\section{MENTAL PLASTICITY AND PSYCHEDELICS}

There is growing evidence that psychedelic therapy promotes a variety of interrelated psychological traits (see Table 1) associated with better mental health outcomes and resilience to adversity, 


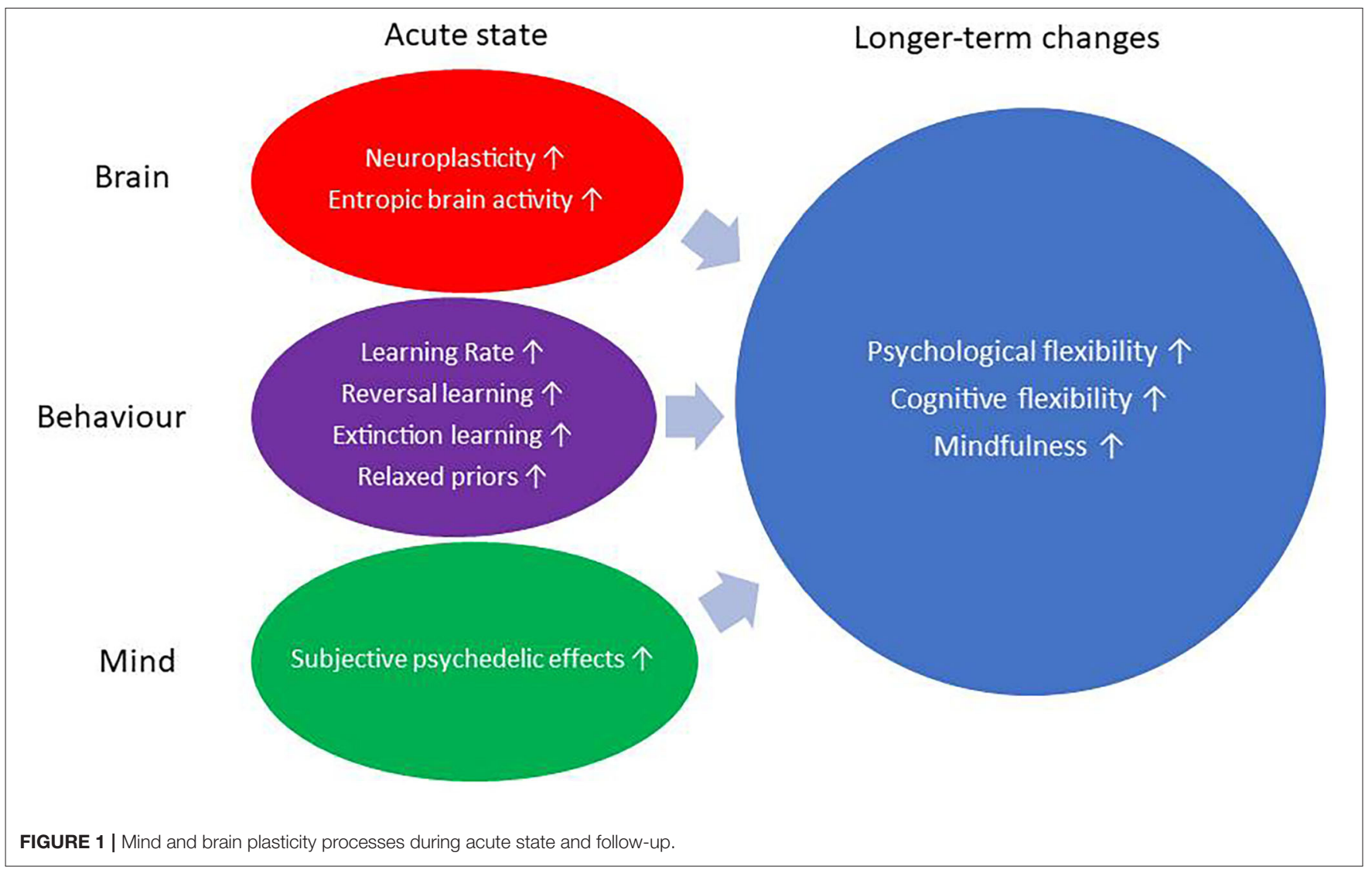

TABLE 1 | Table collating references to psychedelic or psychedelic-relevant studies showing increases in the relevant psychological constructs of processes of change.

\begin{tabular}{|c|c|c|c|c|}
\hline Psychological flexibility $\uparrow$ & Cognitive flexibility $\uparrow$ & Mindfulness capabilities $\uparrow$ & Other relevant constructs $\uparrow$ & $\begin{array}{l}\text { Evidence for construct } \\
\text { interrelations }\end{array}$ \\
\hline $\begin{array}{l}\text { Davis et al. (43) } \\
\text { Close et al. (79) } \\
\text { Watts and Luoma (80) } \\
\text { Zeifman et al. (under review) } \\
\text { Belser et al. (81) }\end{array}$ & $\begin{array}{l}\text { Murphy-Beiner and Soar } \\
(82) \\
\text { Boulougouris et al. (83) } \\
\text { King et al. (84) }\end{array}$ & $\begin{array}{l}\text { Murphy-Beiner and Soar (82) } \\
\text { Domínquez-Clavé et al. (85) } \\
\text { Sampedro et al. (86) } \\
\text { Soler et al. (87) } \\
\text { Uthaug et al. (88) } \\
\text { Uthaug et al. (89) }\end{array}$ & $\begin{array}{l}\text { Resilience: } \\
\text { Brachman et al. (90) } \\
\text { Creativity: } \\
\text { Frecska et al. (91) } \\
\text { Insight: } \\
\text { Noorani et al. (92) } \\
\text { Connectedness: } \\
\text { Watts et al. (93) } \\
\text { Extinction and associative } \\
\text { learning: } \\
\text { Catlow et al. (94) } \\
\text { Openness to experience: } \\
\text { Erritzoe et al. (95) }\end{array}$ & $\begin{array}{l}\text { Levin et al. (96) } \\
\text { McCracken and Velleman } \\
\text { (97) } \\
\text { Moore and Malinowski (98) } \\
\text { Lebude et al. (99) } \\
\text { Tomac (100) } \\
\text { Coffey et al. (101) } \\
\text { Biglan et al. (2008) } \\
\text { Waugh et al. (102) }\end{array}$ \\
\hline
\end{tabular}

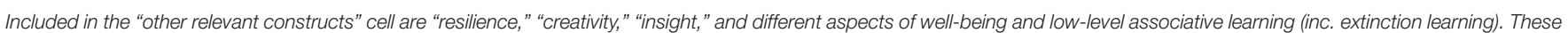

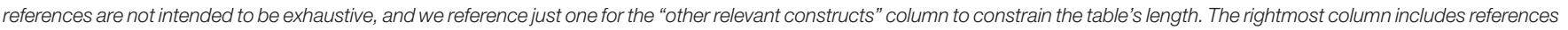

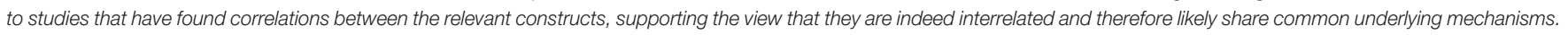

including psychological $(79,93)$ and cognitive flexibility (82, 103) and mindfulness (86-88) (see Table 1). The increase in these traits may be related to the quality of the acute subjective psychedelic experience, which includes such phenomena as "ego-dissolution" (104), near-death experience (105), emotional breakthrough (106), psychological insight (107), non-dual or unitive states (108), and other aspects of mystical or spiritual type experience (109). This list is not intended to be exhaustive but can rather serve as a heuristic for linking other potentially relevant psychological phenomena-which we do, to some extent, below.

We hypothesize that the processes of psychological change catalyzed by the pharmacological action of a psychedelic depend in large part on the triggering of plasticity. In a similar way to how the term "phenotypic plasticity" is used in evolutionary 
science, we use the term "mental plasticity" to refer to an individual's capacity to change his/her mind and/or behavior. Although this term is not established in the scientific literature, we believe it is a simple and useful term that is in-keeping with dictionary definitions and therefore makes no category error. We view mental plasticity as a psychological counterpart to brain plasticity or "neuroplasticity" - for which there are some wellestablished biomarkers. Many established and familiar markers of neuroplasticity are anatomical (110); but valid molecular (111) and functional markers (112) also exist. Some examples of mental plasticity and how they relate to mental health, and research with psychedelics, are discussed below. As highlighted above, for focus, we pay selective attention to psychological phenomenon linked to mental health.

\section{Psychological Flexibility}

Psychological flexibility has been recently defined as the ability to feel and think with openness, to attend voluntarily to one's experience of the present moment, and to move one's life in directions that are important to him/her, building habits that allow him/her to live life in accordance with his/her values and aspirations [95, p. 5]. A six-component "Hexaflex" model has been conceived to describe processes relevant to psychological flexibility, and these include (1) acceptance (the inverse of experiential avoidance); (2) cognitive fusion (attaching thoughts to stimuli); (3) present moment awareness (closely related to "mindfulness"); (4) flexible perspective taking (self-ascontext); (5) contact with values; and (6) committed action (113115). The inverse of psychological flexibility, i.e., "psychological inflexibility," has been described as a transdiagnostically relevant pathological phenomenon (116), associated with psychological distress (114), as well as with high cognitive and behavioral rigidity in depression (117), anxiety (118), and personality; substance use; and eating and obsessive-compulsive disorders (117) - all of which are candidate targets for psychedelic therapy $(38,40,41,47,59,119,120)$. Cognitive fusion, the attachment of stereotyped thought to certain stimuli, is a key dimension of psychological inflexibility (121). Intuitively, cognitive fusion is mechanistically consistent with the phenomenon of canalization, i.e., in the psychological sense, the buttressed routing of certain styles of thinking and/or behaving, so that they become rigid and resistant to change.

Psychological inflexibility overlaps strongly with the related construct "experiential avoidance" (122). Indeed, like "emotional acceptance" (93), psychological flexibility refers to an individual's capacity for staying in contact with experiences eliciting negative emotions (i.e., emotional "acceptance") as well as his/her commitment to living congruently with his/her own values (123). As indicated by this behavioral component, psychological flexibility is a focal construct for acceptance and commitment therapy (ACT), a "third wave" behavioral therapy (121, 124, 125), overlapping in theory and approach with mindfulness-based therapies (115).

It has been proposed that psychological flexibility and ACT are transdiagnostically relevant and conducive to long-term psychological wellness when promoted or practiced $(121,123)$. While not always an explicitly identified target, it has been proposed that psychological flexibility is a common component underlying several effective psychotherapeutic interventions (123). Increased interest in third-wave (126) and process-based (36) therapies, psychological flexibility (36), mindfulness (127), and contemplative practice in the West (128) parallels a rising interest in positive psychology (124)-reflective of common conceptual (129) - and mechanistic foundations.

Of the six "Hexaflex" processes, the acceptance component, defined as the "ability to allow and make space for all of one's internal experience, including thoughts, feelings, and sensations" (115), was identified as a key mediating factor in a qualitative analysis of patient-therapist interviews after participation in a clinical trial involving psilocybin therapy for treatment-resistant depression (TRD) (93). Increased experiential acceptance was also identified as salient in the ritual use of ayahuasca in the treatment of addictions (130) as well as in psilocybin therapy for end-of-life distress (81). A post-treatment increase in "connectedness" (131) and an expanded emotional range also emerged from a thematic analysis of 15 qualitative studies exploring patients' experience with psychedelics in the treatment of psychiatric disorder (107).

By supplementing these findings using the Brief Experiential Avoidance Questionnaire in a naturalistic, observational study, decreased experiential avoidance was found up to 1 month after psychedelic use in two large and separate populations (66). With the use of the Acceptance and Action Questionnaire-II (AAQII) in a separate sample but related design, consistent increases in overall psychological flexibility were seen (79); and in an independent retrospective survey study, psychological flexibility measured via the AAQ-II was found to mediate therapeutic changes after psychedelic experiences with various different compounds (132).

In summary, psychological flexibility is hypothesized to be a transdiagnostically relevant therapeutic phenomenon (116) linked to a specific therapeutic approach (i.e., ACT) that has been proposed to hold prophylactic value (121). It has also been proposed that ACT and the promotion of psychological flexibility in particular integrate well with psychedelic therapy $(80,115,133$, 134). Psychological flexibility also served as a guiding theme in a developing approach to psychedelic psychotherapy referred to as “Accept, Connect, Embody” or “ACE” (80).

\section{Cognitive Flexibility}

Cognitive flexibility is a separate construct to psychological flexibility with a more experimental and translational heritage. It has been defined as "the ability to switch attention from one aspect of an object to another" (135). Cognitive flexibility is most often measured using behavioral paradigms that explore set-shifting and problem solving (136). Compared with psychological flexibility, cognitive flexibility is more closely linked with perseveration (its inverse) and is less overtly tied to psychopathology and therapeutic processes, although these connections have certainly been made (137). In the context of cognitive reappraisal strategies, individuals exhibiting high cognitive inflexibility struggle with switching attention away from internally focused negative rumination (138). Indeed, 
ruminative thought patterns in depression are closely related toor indeed characterized by-cognitive inflexibility (138). There is evidence that cognitive flexibility is deficient in patients with eating disorders (139), general anxiety disorder (140), depression (117), autism (141), addiction (137), and obsessive-compulsive disorder (117) but may be enhanced by mindfulness-based treatments (140). There is also a link between positive mood and cognitive flexibility (142). It may be noteworthy that all of the above-listed disorders have been identified as viable indications for psychedelic therapy.

Increased cognitive flexibility has been observed $24 \mathrm{~h}$ after ayahuasca experience (82). Mixed findings were observed during the acute phase of LSD experience, with one study finding impaired cognitive flexibility (143) and another showing minimal effects on reversal learning (a construct closely associated with cognitive flexibility) in humans (144) - although some aspects of reward related learning were accelerated in this latter study, consistent with a clear, serotonin $2 \mathrm{~A}$ receptor (5-HT2AR)dependent acceleration of learning rate induced via LSD in rabbits (103). The 5-HT2AR is the key receptor site of action for psychedelics, where they function as agonists (145).

Reversal learning has been found to be enhanced by LSD in rodents (84). More evidence for an involvement of the 5-HT2AR in relation to reversal learning (146) includes the finding that antagonism of the 5-HT2AR promoted perseveration, reflective of cognitive inflexibility in rats (83) and rabbits (103). In humans, individuals with anorexia appear to exhibit both lower levels of 5-HT2AR expression (147-149) and lower cognitive flexibility than healthy controls (150). Several atypical antipsychotics possess 5-HT2AR antagonist properties (151); however, beyond some efficacy in parkinsonian (152) and dementia-related psychosis (153), there is little evidence that selective 5-HT2AR antagonists have appreciable efficacy for treating schizophrenia (154). That some effective antidepressant drugs have 5-HT2AR antagonist properties may be explained by their possession of a different (and in some ways inverse) therapeutic mechanism than is associated with psychedelic therapy, i.e., promoting an affective blunting conducive to symptom reduction vs. a psychotherapeutically mediated affective release conducive to symptom reduction plus ancillary benefits $(44,155)$.

Future work is needed to determine whether changes in cognitive flexibility with psychedelics are dose and context dependent. For example, one can imagine how cognitive fusion or perseveration (e.g., intrusive and repeating thoughts) could occur under psychedelics in a particular context, and this may be more likely during cognitive tasks that are improperly understood or difficult to implement due to a general, dose-dependent, non-specific (impairing) effect of the drug on cognitive function (156). Moreover, high doses might impair cognitive flexibility, while lower doses could conceivably enhance it.

So-called "divergent thinking" (157) and cognitive persistence (the persistent exploration of combinations of associations) have been identified as key factors constituting the creative process (158), and a link between cognitive flexibility, divergent thinking, and creativity has been made before (159-163). There is some empirical evidence $(91,164-166)$ and conceptual work (167-170) linking psychedelics with the promotion of aspects of the creative process. Nevertheless, creativity is a notoriously difficult phenomenon to satisfactorily define, and available research involving psychedelics is suggestive rather than confirmatory. Future studies may better dissect the interaction between psychedelics and creativity, as well as how this relates to mental health.

The personality trait "openness to experience" is relevant to the notion of mental plasticity (171). It has been shown to be positively correlated with divergent thinking and creativity (171), cognitive flexibility (172), and psychological flexibility (123). It was said by the founders of the Big Five assessment that open individuals "seek out novelty and variety and have a marked preference for complexity"; thus, open individuals are inclined toward curiosity and new experience (173).

Increased openness has been observed in clinical trials with LSD (174, 175), psilocybin therapy for TRD (95), and 3,4-methylenedioxymethamphetamine (MDMA)-assisted therapy for post-traumatic stress disorder (PTSD) (176). A relationship between acute "mystical-type experience" and subsequent increases in trait openness when it was assessed over 1 year after the psilocybin session has been observed (78). Although we consider openness to experience an interesting phenomenon in regard to the theme of mental plasticity, there is mixed evidence on its relationship with mental health (177). One possible direction for future studies may be to examine differential changes in the different subfactors of openness to experience (177).

\section{Mindfulness}

Mindfulness has a heritage in Buddhist practice and philosophy (127). Mindfulness has been defined as the process of regulating attention with the aim of bringing its focus onto one's current experience, observing lived experience with curiosity, openness and acceptance, and also processing gained insights (178). A widely used five-facet operationalization sees mindfulness as the capacity to (1) observe, (2) describe, and (3) act with awareness of present moment experience, with a (4) non-judgmental and (5) non-reactive attitude (179). Mindfulness has been framed as a construct that overlaps with emotional regulation (101) and some processes of psychological flexibility (180).

Mindfulness has been widely studied and applied in diverse areas, and mindfulness-based techniques have been found to be useful in the treatment of mental illness and promotion and protection of psychological well-being (178). Mindfulness encourages the abandonment of ineffective experiential avoidance strategies and adoption of an adaptive response to stress (178). Mindfulness capacity has been shown to be positively correlated with psychological $(96,97)$ and cognitive flexibility (98) as well as creativity (99) and resilience (100).

Open-label observational studies have explored the effect of ayahuasca on mindfulness capacities as measured by the Five-Facet Mindfulness Questionnaire (FFMQ) (179). Significant increases in some mindfulness capacities were observed $24 \mathrm{~h}$ after ayahuasca, specifically in non-judgmental and nonreactive processing and observing (85) as well as acting with awareness (86-88). Relatedly, in a controlled study using natural 
language processing applied to participant responses during semi-structured interviews, participants on LSD were found to use fewer references to the past-suggestive of a more present-centered state. Moreover, this effect correlated negatively with default-mode network connectivity-a network related to daydreaming or "mental time-travel"-in some ways the opposite phenomenon to mindfulness (181). Another recent open-label observational study showed significant increases in mindfulness capacities after inhaling secretion from the parotoid gland of the Bufo alvarius toad, which contains the serotonergic psychedelic 5-methoxy- $N, N$-dimethyltryptamine (5-MeO-DMT) (89).

\section{The Acute Psychedelic Experience}

There exists a large body of evidence to support the principle that the quality of an individual's acute experience under a psychedelic reliably predicts and mediates longer-term psychological outcomes-including changes in mental health outcomes (182-184) as well as other trait factors $(78,95,185)$. There is also evidence to suggest that certain traits, such as absorption (186) and contextual framing or priming (109), can shape both the intensity (183) and nature of this experience $(29,109,183)$. Perspectives differ on how best to refer to intense subjective experiences under psychedelics. Some prefer the more secular term "peak experience" - with its origins in Abraham Maslow's work (182)—while the term "mystical-type experience," as measured through the "mystical experience questionnaire," is preferred by others $(38,74,109,187)$.

A progressive step toward framework agnosticism might be to focus on the mechanisms underlying such experiences. In this regard, the term "unitive experience" has a good theoretical and empirical heritage $(188,189)$ as well as an intuitively mechanistic appeal $(62,190)$. Feelings of unity, universal interconnectedness, or oneness are closely related to the constructs of non-dual awareness (191) and ego-dissolution (104, 108, 192), which have developing empirical and neurobiological foundations $(185,193$, 194) and have a heritage in Eastern philosophy and practice $(195,196)$.

Unitive or non-dual states of consciousness, marked by "egodissolution" and a sense of oneness or interconnectedness, sometimes framed as "peak" or "mystical-type" experiences, are reliably induced by psychedelics in a dose-dependent manner $(104,108,109)$. As has been empirically shown, at the level of global brain function, one might expect to observe this effect reflected in a flattened energy or attractor landscape (197), consistent with a system that is both globally interconnected and desegregated (190) as well as more supple, pliable, and "free" in its functioning, i.e., being capable of visiting a broader repertoire of sub-states-rather than being confined to just a few dominant ones (198, 199). A range of recent neuroimaging studies with psychedelics have lent significant support to this characterization of brain function under psychedelics (190, 193, 194, 200-202).

In what follows, we review findings of increased neuronal plasticity via psychedelics and finally seek to integrate the relevant material into a comprehensive "process of change" model that places acute and (potentially) subacute increase in mind and brain plasticity at the core of a potentially long-term therapeutic change.

\section{NEUROPLASTICITY}

According to one definition, neuroplasticity is the ability of the nervous system to reorganize its structure, function, and connections in response to a changing environment or a shifting set of demands, thus constituting the mechanism of neuronal adaptability (203-205). In mental health disorders and certain neurological conditions (206), the (mal)adaptive strengthening of specific neural circuits can underlie dysfunctional patterns of thought, emotion, cognition, and behavior (204); moreover, functional organization can appear atypically modular, segregated, or inflexible in low mood states and in populations of people with depression $(207,208)$. Chronic stress has been found to disrupt neuroplasticity $(203,209)$ but may also promote it $(155,199)$. Some psychiatric treatments, e.g., antidepressant drugs (203), ketamine (210), and psychedelics in particular (110, 211-213), appear to promote neuroplasticity, albeit in inconsistent brain regions, e.g., the hippocampus with selective serotonin reuptake inhibitors (SSRIs) and in the cortex, in particular, with psychedelics.

Based on their ability to promote cortical neuroplasticity (110), a new name for psychedelics has been recently proposed: "psychoplastogens" (212). A variety of interventions for mental illness appear to promote neuroplasticity, including monoaminergic antidepressants (214), transcranial magnetic stimulation (204), and mindfulness meditation (215). Congruently, two independent studies have found that the intensity of psychotomimetic and dissociative symptoms experienced during ketamine-infusion positively correlated with its sustained antidepressant effects $(210,216,217)$-which is assumed to be mediated by the rapid induction of neuroplastic effects (210)—although see also Olson (218). The paradox of an acute "psychotomimesis" mediating a subsequent therapeutic change is relevant here, as it is to classic psychedelics (174).

Perhaps the most compelling evidence for increased neuroplasticity post-psychedelics derives from a recent study that found increased synaptogenesis with a range of different classic serotonergic psychedelics, ketamine and MDMA (110). Separately, a doubling of a marker of neuroplasticity, brainderived neurotrophic factor (BDNF), was found in the cortex of rodents after exposure to a psychedelic in two separate studies (211, 219), but inconsistent results have been found in the hippocampus $(94,220)$. A recent gene expression study found clear evidence of increased plasticity gene expression in the cortex with psilocybin with some evidence for related effects in the hippocampus (213).

Constituents of ayahuasca have been linked to neurogenesis in vitro (although not via the main psychedelic constituent, DMT) (221), and a particular dose range of psilocybin has been found to promote extinction learning in mice (94) as well as a 5-HT2ARdependent acceleration of association learning rates in rabbits (103). A further recent study found that proliferation of basal progenitor cells was under the control of 5-HT2AR stimulation 
and disproportionately so in humans relative to evolutionarily "lower" (i.e., by cortical mass) mammals (222), and other recent evidence has shown a role for 5-HT2AR signaling in neurite development (223).

As may be true of plasticity more broadly (224), neuroplasticity may be "outcome-agnostic" (19), in the sense that it could arguably just as easily mediate pathogenesis as salutogenesis or wellness-consistent with the so-called "plastic paradox" (205). This paradox relates to the essential role played by context in determining outcomes from psychedelic therapy (29) as well as recent conceptions of the role of serotonin in mediating mental health outcomes (225). See here for a thorough review of these themes (19).

\section{Entropic Brain}

The network level changes described above may relate to the dysregulation of ongoing brain activity $(194,226)$ and an associated increase in entropy or complexity of spontaneous population level neural activity $(185,227-229)$-as captured by the "entropic brain" hypothesis $(228,230)$. Based on the hypothesis that a broad range of psychiatric disorders feature inflexible brain dynamics, it has been proposed that psychedelics first dysregulate spontaneous brain activity and then allow it to reset or recalibrate in a less aberrant, more typical way (62, $119,231)$. A related "reset" (119) or recalibration analogy for the therapeutic mechanisms of psychedelic therapy has recently been supported by brain imaging findings after psilocybin therapy for TRD (231). A period of emotional equanimity and well-being, referred to as an "after glow," is often reported in the daysweeks following a psychedelic experience (86). Future work is required to better determine the neurobiological character of the relevant processes and phenomena here, including the putative reset/recalibration, as well as "after-glow" effects [but see (62)].

It is tempting to infer that the entropic effects observed acutely under psychedelics are reflective of a functional neuroplasticity that is a mediating vehicle for the relevant longer-term psychological changes that are the focus of this review [e.g., see (185)]. Psychedelics may hijack key neuronal adaptability mechanisms by directly activating them via the 5-HT2AR (62). Within this model, entropic spontaneous brain activity is just one level of a multilevel, generic brain and mind plasticity (229).

\section{TOWARD A UNIFIED PROCESS OF CHANGE MODEL}

So far, we have reviewed relevant phenomena and observations of mind and brain plasticity linked to psychedelic use and therapy. We now attempt to synthesize these various phenomena into a multilevel "process-of-change" model. This model takes inspiration from the Bayesian brain or predictive-coding mechanisms, and particularly how it has been applied to the action of psychedelics (62). In brief, we propose that the main benefit of either the acute neurobiological or psychological effects of psychedelics is the opening of a window of plasticity for a therapeutic change. This can be accomplished through an appropriately supportive context, enabling the mind and brain to be recalibrated in a more adaptive and healthier way (19).

We begin by speculating that entropic brain effects of psychedelics (230) are related to increases in more established markers of neuroplasticity $(110,213,219)$ as well as their core therapeutic effects. 5-HT2ARs are densely expressed in the cortex (232) - where increased plasticity has been most compellingly demonstrated post psychedelic $(213,220)$. One can imagine how entropic brain activity could service an accelerated learning rate (103), including accelerated extinction learning (94). It is easy to intuit that such conditions would be conducive to the relaxation and revision of canalized thoughts and behaviors linked to various psychiatric disorders. Previous work has framed such canalization and its sensitivity to psychedelic therapy in a predictive coding manner, where canalized thought and/or behavior would be related to excessive precision-weighting on "priors" (i.e., internal predictive models that encode implicit assumptions), and these become relaxed or "de-weighted" through the entropic action of psychedelics (62) in combination with therapy (19). While useful only as a metaphor, the last author has used a shaken "snow globe" analogy to refer to the entropic brain action of psychedelics and subsequent psychological recalibration process.

Setting some context for these ideas, the paradox of destabilization or dysregulation being a requirement for a learning process serving therapeutic growth is not entirely anomalous in medicine or cognitive and computer science (233). For example, periods of destabilization in the psychotherapeutic process have been found to predict better eventual outcomes (234), and a transient worsening of the symptoms can sometimes precede therapeutic breakthrough (235) - a process referred to historically as a "healing crisis" (236). It is logical that the process of breaking down canalized thought/affect/attitudes/behavior will evoke anxiety-but if appropriately prepared for and "surrendered to" (237), it may also be welcomed, e.g., as an opportunity for therapeutic growth or learning (106).

Psychological flexibility, and especially its component "cognitive fusion," fits neatly within the above-described prediction coding model, where psychedelic therapy is proposed to relax over-weighted mental and neuronal habits or "priors" (62). In mental illness, certain defensive habits would be expected to have a gravitationally attracting influence, routing thought and behavior in a particular way. From a dynamical systems perspective, the notion of a "limit cycle" is relevant here (238). Examples of canalized thought or behavior in mental illness include ruminative thinking, obsessive thoughts, or compulsive behavioral patterns. Cognitive de-fusion nicely captures the mechanism of effective psychedelic therapy being outlined here. With proper psychological preparation, support, and integration, an individual's psychedelic process is guided toward the ideal of enhanced long-term psychological flexibility $(80,115)$, through the vehicle of an acute brain and mind plasticity aiding a healthy learning process. From a dynamical systems perspective, the image of a flattening energy landscape is relevant (200).

It is common for individuals who have had a psychedelic experience to report personal or transpersonal insights (107). Indeed, such insights are often regarded as being another major 
mediating vehicle for subsequent psychological transformation (62) and speak to the principle of psychedelics enhancing a learning process. Insight and emotional breakthrough are common features of psychedelic experiences and are recognized components of effective psychotherapy more generally (239). In the context of psychedelic therapy, their occurrence strongly predicts positive long-term clinical outcomes $(69,182)$. The opening-up of a new perspective may be a common consequence of an acute entropic brain effect (185) - and recent evidence of increased bottom-up information flow under psychedelics hints at relevant mechanisms by which insight may occur, namely, reduced top-down and increased bottom-up information flow (240).

Why do cognitive fusion, canalization, and the over-weighting of priors occur at all? It has been proposed elsewhere that the development of psychological rigidity is an adaptive response to psychological distress linked to actual or perceived adversity. In psychological terms, cognitive fusion may be conceived of as a defense mechanism (28), where its function is to counteract feelings of distress and uncertainty (28). Feelings of uncertainty and helplessness are, of course, a feature of early life (241), reflecting a critical period of brain development and neuroplasticity in which life experiences have an exaggerated impact on the developing mind and brain (242)-helping explain why early life adversity is such a strong predictor of later life psychopathology (16). Maladaptation to adversity is not an inevitability of course, e.g., as reflected by posttraumatic growth (243). It is telling in this context that greater scores of psychological flexibility are associated with lower scores of post-traumatic stress and higher scores of post-traumatic growth (244). See also Brouwer and CarhartHarris (19).

Lastly, we have noted that brain regions showing the densest expression of 5-HT2AR (232) are also regions that show the longest-range cortico-cortical connections (245), the lightest myelination (246), and the highest intersubject variation in functional connectivity (245). These regions process longer temporal sequences of information (247) and more abstract semantic material $(245,248)$. They are most spatially removed regions from unimodal cortex $(249,250)$, show a consistent gene expression (251), have undergone greatest evolutionary expansion, from primate to human $(246,252)$, and show the greatest expansion throughout ontogenetic development.

These regions also feature more aerobic glycolysis (253) and amyloid deposition than elsewhere in the cortex (254). Recent findings suggest that cortical expansion may be under the control of 5-HT2AR signaling (222) and 5-that this signaling also plays an important role in neurite development (223). We highlight these interrelated properties as they imply an important role for the 5-HT2AR in activating and accelerating growth at various stages of life. Evidence linking 5-HT2AR signaling with the evolution of the human brain is particularly intriguing, raising questions about when and why a deepening of mind and brain plasticity could be advantageous to our species, as a transient state (e.g., the psychedelic state being a drug-induced hyperplastic state), a carryover effect of such states, or a more tonic quality of plasticity. See Brouwer and Carhart-Harris (19) for a relevant discussion.

\section{DISCUSSION}

This paper has reviewed literature supporting the claim that psychedelic therapy may have prophylactic or preventative potential in mental healthcare, and a related transdiagnostic therapeutic action, focused on increased brain and mind plasticity. We have supplemented these claims by presenting a process of change model that can be used as a template for investigating and understanding how psychedelic therapy possesses these valuable properties. More specifically, we have proposed that via an acute state of heightened mental and neuronal plasticity, flanked by psychological support designed to shepherd psychological growth or learning in a therapeutic direction, psychedelic therapy targets a core dimension of mental health that traverses diagnostic boundaries, including the one between health and illness. We have used a predictive processing framework to describe this "process-of-change" model, where acute plasticity combined with psychological support is utilized to promote a healthy re-learning, where what is re-learnt is an equanimous, open, and psychologically flexible state of being. This process could be described as a recalibrationof brain, mind, and behavior-serving current and long-term psychological health.

In terms of limitations, the present paper has not sought to critically appraise our central hypothesis that psychedelic therapy can aid prophylaxis or possess a transdiagnostic action. It can therefore be fairly criticized for cherry-picking findings supportive of its central narrative. We also acknowledge that while we have presented a process of change model, as yet few studies have been done that can directly connect the various model components in the same population, e.g., acute brain plasticity (in its various forms) with entropic brain activity and pre- vs. post-psychedelic changes in relevant psychological and neurobiological domains, such as psychological flexibility. The paper could also be criticized for being too cognitive-centric.

One relevant recent debate concerns the question of whether acute subjective effects are necessary for longer-term therapeutic outcomes, with one view being they may be useful but not essential (218) and another view favoring their essentialness (255). A related question concerns whether and by what magnitude does positive expectancy drive therapeutic outcomes. Positive expectancy is often wrongly referred to as the "placebo effect" - a term that should strictly be reserved for positive expectancy driving positive outcomes from an inert intervention. Our assumption is that positive expectancy is an important contributor to positive outcomes from psychedelic therapy [e.g., see (256)]. Moreover, it seems reasonable to consider it as a harnessable component of the model itself. Perhaps the utilization of positive expectancy could even be considered best practice, and studies that allow for it could be viewed as more ecologically valid than those that attempt to strip it out. Even if positive therapeutic outcomes were to be observed from a non-psychedelic "psychoplastogen," one could not easily rule 
out a role for positive expectancy $(212,257)$. There may be a number of cautionary factors to consider if psychedelic therapy is to be legitimately explored as a preventative measure-perhaps foremost is the risk of iatrogenesis (258). While controlled and population studies indicate the prevalence of iatrogenic reactions is very rare, it remains plausible and not without precedent that a worsening of mental health after a psychedelic experience is possible (54) - particularly if the drug is used contrary to safety guidelines (259). The risk of hallucinogen-persisting perceptual disorder also needs to be considered, despite its prevalence appearing to be very low (260).

Like others $(29,261,262)$, we have previously highlighted the importance of contextual factors (often referred to as "set and setting") in mediating the outcome of a psychedelic experience, but there may be additional risk factors to consider. Psychological preparation, support, and integration are likely to be essential components of any future therapeutic and prophylactic application of psychedelics, and while some progress has been made in demonstrating the positive influence of preparation and support on subsequent outcomes (183), much more needs to be done, including measuring the role of psychological integration-in its various forms. Thus, based on the same mechanistic principle, in the same way that psychedelics may facilitate adaptive processes, if used improperly, they could potentially augment maladaptive processes, e.g., retriggering trauma and/or associated defense mechanisms - which may manifest as over-weighted or "canalized" priors.

Relatedly, while the maladaptive canalization and associated "too strong priors" model appears to fit well with a broad range of psychiatric disorders and their main symptom clusters, it does not fit them all. For example, autism has been described as a condition in which weak high-level priors permit a hypersensitivity to sensory input/prediction error $(263,264)$; and certain psychotic states, such as delirium, or aspects of early psychosis seem more consistent with a weak prior model. To clarify, with some qualification, psychiatric symptoms consistent with the "too strong priors" model are those we believe to be most amenable to effective treatment via psychedelic therapy, as long there is an acceptably low risk of triggering a catastrophic psychological decompensation if these defensive priors are challenged.

From a dynamical systems theory perspective, it is hypothesized that psychedelics flatten the mind and brain's energy landscape, implying that the gravitational pull of local minima or pathological attractor states is lessened (62). While this scenario is hypothesized to reflect a therapeutic window of opportunity for the subsequent longer-term deweighting/flattening of relevant pathological attractors, we are also mindful that the character of the acute state itself may mirror certain states that could be construed as pathological, such as states of dissolved ego-boundaries in early psychosis (62). Thus, we are cautious about depicting psychedelic therapy as a straightforward intervention or panacea for all psychological ailments. Such an image would not fairly reflect the complexity and nuance of mental illness, nor indeed, psychedelic therapy, which is a particularly complex intervention that is certainly not without risk.

It is worth noting that despite the large number of studies cited to support this paper's central hypothesis, many were observational in nature or controlled but with small sample sizes, and some lacked control conditions altogether or may have failed to entirely maintain the study blind-a common limitation of psychedelic research. The methodologies also varied widely. Regarding the psychological flexibility construct, caution is advised when consulting studies that report strong correlations with mental health, as they have predominantly applied the AAQ-II. Despite the widespread use of this instrument, a number of recent studies (265, 266) articulated an important critique against it, questioning what the AAQ-II tool is actually measuring; e.g., is it psychological flexibility specifically or a more generic reflection of well-being?

An important limitation of the present paper is that we have not been able to cite direct evidence for the hypothesized prophylaxis via psychedelic use or therapy. The most compelling demonstration of prophylaxis would require a longitudinal cohort study that tracks psychedelic "users" and "non-users" across time, while controlling for confounding variables through regression modeling. The above-cited population and prospective observational studies offer the best evidence for the hypothesized prophylaxis, but retrospective sampling is a limitation of the former and self-selecting sample, and attribution biases are a problem with the latter. Our hope is that future large-scale longitudinal cohort studies will include a specific question about psychedelic use.

We are also aware that we have not properly discussed optimal delivery of psychedelic therapy, nor how best to maximize its hypothesized prophylactic potential. Regarding treatment optimization, questions about optimal dosage, frequency of sessions, re-dosing (where indicated), adequate and optimal settings, possible indications and contraindications, which substances work best for what indications and for whom, and the role of age and other characteristics have not been addressed. These matters should be intensively explored in future studies, and this may be done best via adaptive or pragmatic trials (267-269).

Recent proposals that psychedelics could be effectively twinned with so-called "third wave" psychotherapies-e.g., mindfulness-based cognitive behavioral therapy and ACT-are also consistent with the proposal that psychedelic therapy can promote psychological flexibility $(80,125,133,134,180,270)$. Nevertheless, more research on transdiagnostic targets and processes of change is needed (35). One healthy development would be to find that other psychological approaches and constructs converge in a similar way to those of ACT and psychological flexibility and perhaps share consistent underlying (e.g., neurobiological) mechanisms. Reference to literature on gestalt and psychoanalytic constructs such as raising awareness, 
creative adjustment, process and field theory (271), defense mechanisms, transference, splitting, projection, abreaction, ego functions and dysfunctions, and the unconscious (272) could help to broaden and enrich our understanding of psychedelic therapy and its mechanisms.

We have proposed that psychedelic therapy represents a promising new therapeutic strategy for treating, enhancing, and maintaining mental health that transcends diagnostic boundaries. We have cited direct evidence for these properties and offered an interdisciplinary "process-of-change" model to explain them. The model is based on a synthesis of theories and observations from psychology and neuroscience, where it is proposed that psychedelics promote an acute state of heightened mind and brain plasticity enabling psychological interventions to work more effectively. We propose that a pharmacologically mediated increase in plasticity provides an opportunity for relaxing and revising canalized habits of mind, brain, and behavior. The present perspective is consistent with the position that mental healthcare and research require a paradigm shift away from solely palliative or reactive "solutions" - e.g., by aiming to treat specific symptoms when they become visible at a critical level. We acknowledge potential risks associated with psychedelic therapy and its integration into mainstream mental healthcare and, thus, emphasize the importance of regulated use, as well as the recognition of the essential role played by context (e.g., therapeutic support) when delivering safe and effective psychedelic therapy.

It is our hope that through a careful roll-out of psychedelic medicine, closely aligned with psychedelic science, we may be able to advance our understanding of how mental illness arises and can be mitigated, or prevented, via a particularly deep quality of care. The psychedelic therapy model may be different from previous approaches in mainstream psychiatry in that it recognizes the canalization of thought and/or behavior in response to adversity as a key pathophysiological mechanism and seeks to treat it via enhancing plasticity in combination with nurturing support. Thus, psychedelic therapy is a hybrid drug $\times$ context therapeutic model; indeed, it is a combination treatment. It is our hope that a proper recognition of this may help bridge an unnecessary and outdated pharmacology vs. psychology divide in mental healthcare and research (273).

\section{REFERENCES}

1. Oxford English Dictionary Online (2020). Available online at: https://www. lexico.com/definition/plasticity (accessed June 4, 2021).

2. Haslam N, Mcgrath MJ, Viechtbauer W, Kuppens P. Dimensions over categories: a meta-analysis of taxometric research. Psychol Med. (2020) 50:1418-32. doi: 10.1017/S003329172000183X

3. Syme KL, Hagen EH. Mental health is biological health: Why tackling "diseases of the mind" is an imperative for biological anthropology in the 21st century. Am J Phys Anthropol. (2020) 171:87-117. doi: 10.1002/ajpa.23965

4. WHO (2017). Depression and Other Common Mental Disorders: Global Health Estimates. Geneva: World Health Organization.

\section{DATA AVAILABILITY STATEMENT}

The original contributions presented in the study are included in the article, further inquiries can be directed to the corresponding author.

\section{AUTHOR CONTRIBUTIONS}

RK brought the initial idea and wrote the first draft of the manuscript. RC-H wrote sections of the manuscript and contributed substantially to the development of the proposed theoretical model. All authors contributed to the conception, writing, revising the manuscript critically for important intellectual content, and final approval of the manuscript.

\section{FUNDING}

This study was supported by Charles University programme Progres Q15 Life course, lifestyle and quality of life from the perspective of individual adaptation and the relationship of the actors and institutions, Technological Agency of the Czech Republic within the Program Zéta (project ID: TJ02000156), donation from REDOX s.r.o., grants AZV MZCR NV18-0400260, GACR 17-04047S, GACR 304/18-09296S, AZV NU2004-00389, PharmaBrain CZ.02.1.01/0.0/0.0/16_025/0007444, and project Nr. LO1611 with a financial support from the MEYS under the NPU I program. RC-H was supported by the Alex Mosley Charitable Trust and the Centre for Psychedelic Research, which was supported by founding donations from the Ad Astra Chandaria Trust, Nikean Foundation, Alexander and Bohdana Tamas, and Tim Ferriss (https://www.imperial.ac. $\mathrm{uk} /$ psychedelic-researchcentre/funding-partners/). The funders were not involved in the study design, collection, analysis, interpretation of data, the writing of this article or the decision to submit it for publication.

\section{ACKNOWLEDGMENTS}

RK thanks Rick Doblin for essential support and useful discussions, Marek Preiss for comments on the first draft of the manuscript, and Dominique Lippelt for intellectual insights in the initial phase. We also thank all reviewers of previous versions of the manuscript for enabling us to improve it.

5. WHO (2004). Prevention of Mental Disorders: effective Interventions and Policy Options: Summary Report/a Report of the World Health Organization Dept. of Mental Health and Substance Abuse; in collaboration with the Prevention Research Centre of the Universities of Nijmegen and Maastricht. World Health Organization,.

6. Wainberg ML, Scorza P, Shultz JM, Helpman L, Mootz JJ, Johnson $\mathrm{KA}$, et al. Challenges and opportunities in global mental health: a research-to-practice perspective. Curr Psychiatry Rep. (2017) 19:28. doi: 10.1007/s11920-017-0780-Z

7. Van Gerven J, Cohen A. Vanishing clinical psychopharmacology. Br J Clin Pharmacol. (2011) 72:1-5. doi: 10.1111/j.1365-2125.2011. 04021.x 
8. Uher R, Farmer A, Henigsberg N, Rietschel M, Mors O, Maier W, et al. Adverse reactions to antidepressants. Br J Psychiatry. (2009) 195:20210. doi: 10.1192/bjp.bp. 108.061960

9. Barbui C, Furukawa TA, Cipriani A. Effectiveness of paroxetine in the treatment of acute major depression in adults: a systematic re-examination of published and unpublished data from randomized trials. CMAJ. (2008) 178:296-305. doi: 10.1503/cmaj.070693

10. Al-Harbi KS. Treatment-resistant depression: therapeutic trends, challenges, and future directions. Patient Prefer Adherence. (2012) 6:369. doi: 10.2147/PPA.S29716

11. Cipriani A, Furukawa TA, Salanti G, Chaimani A, Atkinson LZ, Ogawa $\mathrm{Y}$, et al. Comparative efficacy and acceptability of 21 antidepressant drugs for the acute treatment of adults with major depressive disorder: a systematic review and network meta-analysis. Focus. (2018) 16:4209. doi: 10.1176/appi.focus.16407

12. Rush AJ, South C, Jha MK, Jain SB, Trivedi MH. What to expect when switching to a second antidepressant medication following an ineffective initial SSRI: a report from the randomized clinical STAR* D study. J Clin Psychiatry. (2020) 81:19m12949. doi: 10.4088/JCP.19m12949

13. Mchugh RK, Whitton SW, Peckham AD, Welge JA, Otto MW. Patient preference for psychological vs. pharmacological treatment of psychiatric disorders: a meta-analytic review. J Clin Psychiatry. (2013) 74:595. doi: 10.4088/JCP.12r07757

14. Thase ME, Friedman ES. Is psychotherapy an effective treatment for melancholia and other severe depressive states? J Affect Disord. (1999) 54:1-19. doi: 10.1016/S0165-0327(99)00033-6

15. Min J-A, Lee C-U, Lee C. Mental health promotion and illness prevention: a challenge for psychiatrists. Psychiatry Investig. (2013) 10:30716. doi: 10.4306/pi.2013.10.4.307

16. Varese F, Smeets F, Drukker M, Lieverse R, Lataster T, Viechtbauer W, et al. Childhood adversities increase the risk of psychosis: a meta-analysis of patient-control, prospective-and cross-sectional cohort studies. Schizophr Bull. (2012) 38:661-71. doi: 10.1093/schbul/sbs050

17. Felitti VJ, Anda RF. The relationship of adverse childhood experiences to adult medical disease, psychiatric disorders, and sexual behavior: Implications for healthcare. In: Ruth A L, Eric V, Clare P, editors. The Impact of Early Life Trauma on Health and Disease: The Hidden Epidemic. Cambridge: Cambridge University Press (2010). p. 77-87.

18. Anttila V, Bulik-Sullivan B, Finucane HK, Walters RK, Bras J, Duncan L, et al. Analysis of shared heritability in common disorders of the brain. Science. (2018) 360:eaap8757. doi: 10.1126/science.aap8757

19. Brouwer A, Carhart-Harris RL. Pivotal mental states. J Psychopharmacol. (2020) 35:319-52. doi: 10.1177/0269881120959637

20. Werner E. Resilience and recovery: findings from the Kauai longitudinal study. Res Policy Pract Childrens Mental Health. (2005) 19:11-4.

21. Caspi A, Hariri AR, Holmes A, Uher R, Moffitt TE. Genetic sensitivity to the environment: the case of the serotonin transporter gene and its implications for studying complex diseases and traits. Am J Psychiatry. (2010) 167:509-27. doi: 10.1176/appi.ajp.2010.09101452

22. Carhart-Harris RL. Serotonin, psychedelics and psychiatry. World Psychiatry. (2018) 17:358. doi: 10.1002/wps.20555

23. Miyazaki K, Miyazaki KW, Doya K. The role of serotonin in the regulation of patience and impulsivity. Mol Neurobiol. (2012) 45:21324. doi: 10.1007/s12035-012-8232-6

24. Campbell-Sills L, Forde DR, Stein MB. Demographic and childhood environmental predictors of resilience in a community sample. J Psychiatr Res. (2009) 43:1007-12. doi: 10.1016/j.jpsychires.200 9.01 .013

25. Davydov DM, Stewart R, Ritchie K, Chaudieu I. Resilience and mental health. Clin Psychol Rev. (2010) 30:479-95. doi: 10.1016/j.cpr.2010.03.003

26. Coie JD, Watt NF, West SG, Hawkins JD, Asarnow JR, Markman HJ, et al. The science of prevention: A conceptual framework and some directions for a national research program. Am Psychol. (1993) 48:101322. doi: 10.1037/0003-066X.48.10.1013

27. Waddington $\mathrm{CH}$. Canalization of development and genetic assimilation of acquired characters. Nature. (1959) 183:1654-5. doi: 10.1038/1831654a0

28. Carhart-Harris RL. How do psychedelics work? Curr Opin Psychiatry. (2019) 32:16-21. doi: 10.1097/YCO.0000000000000467
29. Carhart-Harris RL, Roseman L, Haijen E, Erritzoe D, Watts R, Branchi I, et al. Psychedelics and the essential importance of context. J Psychopharmacol. (2018) 32:725-31. doi: 10.1177/0269881118754710

30. Sauer-Zavala S, Gutner CA, Farchione TJ, Boettcher HT, Bullis JR, Barlow DH. Current definitions of "transdiagnostic" in treatment development: a search for consensus. Behav Ther. (2017) 48:128-38. doi: 10.1016/j.beth.2016.09.004

31. Dozois DJ, Seeds PM, Collins KA. Transdiagnostic approaches to the prevention of depression and anxiety. J Cogn Psychother. (2009) 23:44. doi: 10.1891/0889-8391.23.1.44

32. Lai HMX, Cleary M, Sitharthan T, Hunt GE. Prevalence of comorbid substance use, anxiety and mood disorders in epidemiological surveys, 19902014: a systematic review and meta-analysis. Drug Alcohol Depend. (2015) 154:1-13. doi: 10.1016/j.drugalcdep.2015.05.031

33. Kessler RC, Sampson NA, Berglund P, Gruber M, Al-Hamzawi A, Andrade $\mathrm{L}$, et al. Anxious and non-anxious major depressive disorder in the World Health Organization World Mental Health Surveys. Epidemiol Psychiatr Sci. (2015) 24:210-26. doi: 10.1017/S2045796015000189

34. Dean CE. Whither research domain criteria? J Nerv Ment Dis. (2019) 207:419-20. doi: 10.1097/NMD.0000000000000985

35. Hofmann SG, Hayes SC. The future of intervention science: process-based therapy. Clin Psychol Sci. (2019) 7:37-50. doi: 10.1177/2167702618772296

36. Hayes SC, Hofmann SG. The third wave of cognitive behavioral therapy and the rise of process-based care. World Psychiatry. (2017) 16:245. doi: 10.1002/wps.20442

37. Hentschel U, Draguns JG, Ehlers W, Smith G, editors. Defense Mechanisms: Current Approaches to Research and Measurement. In: Defense Mechanisms: Theoretical, Research and Clinical Perspectives. Elsevier Science Ltd (2004). p. 3-41. doi: 10.1016/S0166-4115(04)80026-8

38. Garcia-Romeu A, Griffiths RR, Johnson MW. Psilocybin-occasioned mystical experiences in the treatment of tobacco addiction. Curr Drug Abuse Rev. (2015) 7:157-64. doi: 10.2174/1874473708666150107121331

39. Bogenschutz MP, Forcehimes AA, Pommy JA, Wilcox CE, Barbosa PCR, Strassman RJ. Psilocybin-assisted treatment for alcohol dependence: a proof-of-concept study. J Psychopharmacol. (2015) 29:289-99. doi: 10.1177/0269881114565144

40. Moreno FA, Wiegand CB, Taitano EK, Delgado PL. Safety, tolerability, and efficacy of psilocybin in 9 patients with obsessive-compulsive disorder. J Clin Psychiatry. (2006) 67:1735-40. doi: 10.4088/JCP.v67n1110

41. Carhart-Harris RL, Bolstridge M, Rucker J, Day CM, Erritzoe D, Kaelen $\mathrm{M}$, et al. Psilocybin with psychological support for treatment-resistant depression: an open-label feasibility study. Lancet Psychiatry. (2016) 3:61927. doi: 10.1016/S2215-0366(16)30065-7

42. Palhano-Fontes F, Barreto D, Onias H, Andrade KC, Novaes MM, Pessoa JA, et al. Rapid antidepressant effects of the psychedelic ayahuasca in treatmentresistant depression: a randomized placebo-controlled trial. Psychol Med. (2018) 49:655-63. doi: 10.1017/S0033291718001356

43. Davis AK, Barrett FS, May DG, Cosimano MP, Sepeda ND, Johnson MW, et al. Effects of psilocybin-assisted therapy on major depressive disorder: a randomized clinical trial. JAMA Psychiatry. (2020) 78:4819. doi: 10.1001/jamapsychiatry.2020.3285

44. Carhart-Harris R, Giribaldi B, Watts R, Baker-Jones M, Murphy-Beiner A, Murphy R, et al. Trial of psilocybin versus escitalopram for depression. New Engl J Med. (2021) 384:1402-11. doi: 10.1056/NEJMoa2032994

45. Grob CS, Danforth AL, Chopra GS, Hagerty M, Mckay CR, Halberstadt AL, et al. Pilot study of psilocybin treatment for anxiety in patients with advanced-stage cancer. Arch Gen Psychiatry. (2011) 68:71-8. doi: 10.1001/archgenpsychiatry.2010.116

46. Gasser P, Holstein D, Michel Y, Doblin R, Yazar-Klosinski B, Passie T, et al. Safety and efficacy of lysergic acid diethylamide-assisted psychotherapy for anxiety associated with life-threatening diseases. J Nerv Ment Dis. (2014) 202:513-20. doi: 10.1097/NMD.0000000000000113

47. Ross S, Bossis A, Guss J, Agin-Liebes G, Malone T, Cohen B, et al. Rapid and sustained symptom reduction following psilocybin treatment for anxiety and depression in patients with life-threatening cancer: a randomized controlled trial. J Psychopharmacol. (2016) 30:1165-80. doi: 10.1177/0269881116675512

48. Griffiths RR, Johnson MW, Carducci MA, Umbricht A, Richards WA, Richards BD, et al. Psilocybin produces substantial and sustained decreases 
in depression and anxiety in patients with life-threatening cancer: a randomized double-blind trial. J Psychopharmacol. (2016) 30:118197. doi: $10.1177 / 0269881116675513$

49. Reiff CM, Richman EE, Nemeroff CB, Carpenter LL, Widge AS, Rodriguez $\mathrm{CI}$, et al. Psychedelics and psychedelic-assisted psychotherapy. Am J Psychiatry. (2020) 177:391-410. doi: 10.1176/appi.ajp.2019.19010035

50. Butler M, Seynaeve M, Nicholson TR, Pick S, Kanaan RA, Lees A, et al. Psychedelic treatment of functional neurological disorder: a systematic review. Ther $A d v$ Psychopharmacol. (2020) 10:2045125320912125. doi: 10.1177/20451253209 12125

51. Renelli M, Fletcher J, Tupper KW, Files N, Loizaga-Velder A, Lafrance A. An exploratory study of experiences with conventional eating disorder treatment and ceremonial ayahuasca for the healing of eating disorders. Eating Weight Disord Stud Anorexia Bulimia Obes. (2018) 25:43744. doi: 10.1007/s40519-018-0619-6

52. Spriggs MJ, Kettner H, Carhart-Harris RL. Positive effects of psychedelics on depression and wellbeing scores in individuals reporting an eating disorder. Eat Weight Disord. (2020) 26:1265-70. doi: 10.1007/s40519-020-01000-8

53. Ramachandran V, Chunharas C, Marcus Z, Furnish T, Lin A. Relief from intractable phantom pain by combining psilocybin and mirror visual-feedback (MVF). Neurocase. (2018) 24:10510. doi: $10.1080 / 13554794.2018 .1468469$

54. Hausner M, Segal E. LSD: The Highway to Mental Health. ASC Books (2009).

55. Mithoefer MC, Wagner MT, Mithoefer AT, Jerome L, Doblin R. The safety and efficacy of \pm 3 , 4-methylenedioxymethamphetamineassisted psychotherapy in subjects with chronic, treatment-resistant posttraumatic stress disorder: the first randomized controlled pilot study. $J$ Psychopharmacol. (2011) 25:439-52. doi: 10.1177/0269881110378371

56. Nielson JL, Megler JD. Ayahuasca as a candidate therapy for PTSD. In: The Therapeutic Use of Ayahuasca. Berlin; Heidelberg: Springer (2014). p. 41-58.

57. Ossebaard, H., and Maalsté, N. (1999). The Bastiaans method of drugassisted therapy. a preliminary follow-up study with former clients. Zugriff am. 7:2013.

58. Winkler P, Gorman I, Kočárová R. Use of LSD by mental health professionals. In: Preedy VR, editor. Neuropathology of Drug Addictions and Substance Misuse: Stimulants, Club and Dissociative Drugs, Hallucinogens, Steroids, Inhalants and International Aspects. London; San Diego; Cambridge; Oxford: Academic Press (2016).

59. Winkler P, Kočárová R. Psychedelic treatment of disruptive personality patterns. In: Michael JW, Ben S, editors. Advances in Psychedelic Medicine: State-of-the-Art Therapeutic Applications. Santa Barbara, CA; Denver, CO: Praeger (2019). p. 232.

60. Zeifman RJ, Wagner AC. Exploring the case for research on incorporating psychedelics within interventions for borderline personality disorder. $J$ Contextual Behav Sci. (2020) 15:1-11. doi: 10.1016/j.jcbs.2019.11.001

61. Van Mulukom V, Patterson R, Van Elk M. Broadening your mind to include others: The relationship between serotonergic psychedelic experiences and maladaptive narcissism. Psychopharmacology. (2020) 237:2725-37.

62. Carhart-Harris R, Friston K. REBUS and the anarchic brain: toward a unified model of the brain action of psychedelics. Pharmacol Rev. (2019) 71:316-44. doi: 10.1124/pr.118.017160

63. Johansen P- $\varnothing$, Krebs TS. Psychedelics not linked to mental health problems or suicidal behavior: a population study. J Psychopharmacol. (2015) 29:2709. doi: $10.1177 / 0269881114568039$

64. Krebs TS, Johansen PO. Psychedelics and mental health: a population study. PLoS ONE. (2013) 8:e63972. doi: 10.1371/journal.pone. 0063972

65. Hendricks PS, Thorne CB, Clark CB, Coombs DW, Johnson MW. Classic psychedelic use is associated with reduced psychological distress and suicidality in the United States adult population. J Psychopharmacol. (2015) 29:280-8. doi: 10.1177/0269881114565653

66. Zeifman RJ, Wagner AC, Watts R, Kettner H, Mertens LJ, Carhart-Harris RL. Post-psychedelic reductions in experiential avoidance are associated with decreases in depression severity and suicidal ideation. Front Psychiatry. (2020) 11:782. doi: 10.3389/fpsyt.2020.00782

67. Argento E, Braschel M, Walsh Z, Socias ME, Shannon K. The moderating effect of psychedelics on the prospective relationship between prescription opioid use and suicide risk among marginalized women. J Psychopharmacol. (2018) 32:1385-91. doi: 10.1177/0269881118798610

68. Argento E, Strathdee SA, Tupper K, Braschel M, Wood E, Shannon K. Does psychedelic drug use reduce risk of suicidality? Evidence from a longitudinal community-based cohort of marginalised women in a Canadian setting. $B M J$ Open. (2017) 7:e016025. doi: 10.1136/bmjopen-2017-016025

69. Carhart-Harris R, Bolstridge M, Day C, Rucker J, Watts R, Erritzoe D, et al. Psilocybin with psychological support for treatment-resistant depression: six-month follow-up. Psychopharmacology. (2018) 235:399408. doi: 10.1007/s00213-017-4771-x

70. Zeifman R, Palhano-Fontes F, Hallak J, Nunes EA, Maia-DeOliveira JP, De Araujo DB. The impact of ayahuasca on suicidality: results from a randomized controlled trial. Front Pharmacol. (2019) 10:1325. doi: $10.3389 /$ fphar.2019.01325

71. Halpern JH, Sherwood AR, Hudson JI, Yurgelun-Todd D, Pope HG Jr. Psychological and cognitive effects of long-term peyote use among Native Americans. Biol Psychiatry. (2005) 58:624-31. doi: 10.1016/j.biopsych.2005.06.038

72. Bouso JC, González D, Fondevila S, Cutchet M, Fernández X, Barbosa PCR, et al. Personality, psychopathology, life attitudes and neuropsychological performance among ritual users of ayahuasca: a longitudinal study. PLoS ONE. (2012) 7:e42421. doi: 10.1371/journal.pone.00 42421

73. Jungaberle H, Thal S, Zeuch A, Rougemont-Bücking A, Von Heyden M, Aicher $\mathrm{H}$, et al. Positive psychology in the investigation of psychedelics and entactogens: a critical review. Neuropharmacology. (2018) 142:17999. doi: 10.1016/j.neuropharm.2018.06.034

74. Griffiths RR, Johnson MW, Richards WA, Richards BD, Jesse R, Maclean KA, et al. Psilocybin-occasioned mystical-type experience in combination with meditation and other spiritual practices produces enduring positive changes in psychological functioning and in trait measures of prosocial attitudes and behaviors. J Psychopharmacol. (2018) 32:4969. doi: $10.1177 / 0269881117731279$

75. Lyons T, Carhart-Harris RL. Increased nature relatedness and decreased authoritarian political views after psilocybin for treatment-resistant depression. J Psychopharmacol. (2018) 32:811-9. doi: 10.1177/0269881117748902

76. Kettner H, Gandy S, Haijen EC, Carhart-Harris RL. From egoism to ecoism: psychedelics increase nature relatedness in a state-mediated and context-dependent manner. Int J Environ Res Public Health. (2019) 16:5147. doi: 10.3390/ijerph16245147

77. Bouso JC, Dos Santos RG, Alcázar-Córcoles MÁ, Hallak JE. Serotonergic psychedelics and personality: a systematic review of contemporary research. Neurosci Biobehav Rev. (2018) 87:118-32. doi: 10.1016/j.neubiorev.2018.02.004

78. MacLean KA, Johnson MW, Griffiths RR. Mystical experiences occasioned by the hallucinogen psilocybin lead to increases in the personality domain of openness. J Psychopharmacol. (2011) 25:1453-61. doi: 10.1177/0269881111420188

79. Close JB, Hajien EC, Watts R, Roseman L, Carhart-Harris RL. Psychedelics and psychological flexibility-Results of a prospective web-survey using the Acceptance in Action Questionnaire II. J Context Behav Sci. (2020) 16:3744. doi: $10.1016 /$ j.jcbs.2020.01.005

80. Watts R, Luoma J. The use of the psychological flexibility model to support psychedelic assisted therapy. J Contextual Behav Sci. 15:92-102.

81. Belser AB, Agin-Liebes G, Swift TC, Terrana S, Devenot N, Friedman HL, et al. Patient experiences of psilocybin-assisted psychotherapy: an interpretative phenomenological analysis. J Hum Psychol. (2017) 57:35488. doi: $10.1177 / 0022167817706884$

82. Murphy-Beiner A, Soar K. Ayahuasca's 'afterglow': improved mindfulness and cognitive flexibility in ayahuasca drinkers. Psychopharmacology. (2020) 237:1161-9. doi: 10.1007/s00213-019-05445-3

83. Boulougouris V, Glennon JC, Robbins TW. Dissociable effects of selective 5HT 2A and 5-HT 2C receptor antagonists on serial spatial reversal learning in rats. Neuropsychopharmacology. (2008) 33:2007. doi: 10.1038/sj.npp.1301584

84. King A, Martin I, Seymour K. Reversal learning facilitated by a single injection of lysergic acid diethylamide (LSD 25) in the rat. Br J Pharmacol. (1972) 45:161P. 
85. Domínguez-Clavé E, Soler J, Pascual JC, Elices M, Franquesa A, Valle M, et al. Ayahuasca improves emotion dysregulation in a community sample and in individuals with borderline-like traits. Psychopharmacology. (2019) 236:573-80. doi: 10.1007/s00213-018-5085-3

86. Sampedro F, De La Fuente Revenga M, Valle M, Roberto N, DomínguezClavé E, Elices $M$, et al. Assessing the psychedelic "after-glow" in ayahuasca users: post-acute neurometabolic and functional connectivity changes are associated with enhanced mindfulness capacities. Int J Neuropsychopharmacol. (2017) 20:698-711. doi: 10.1093/ijnp/ pyx036

87. Soler J, Elices M, Franquesa A, Barker S, Friedlander P, Feilding A, et al. Exploring the therapeutic potential of Ayahuasca: acute intake increases mindfulness-related capacities. Psychopharmacology. (2016) 233:823-9. doi: 10.1007/s00213-015-4162-0

88. Uthaug M, Van Oorsouw K, Kuypers K, Van Boxtel M, Broers N, Mason $\mathrm{N}$, et al. Sub-acute and long-term effects of ayahuasca on affect and cognitive thinking style and their association with ego dissolution. Psychopharmacology. (2018) 235:2979-89. doi: 10.1007/s00213-01 8-4988-3

89. Uthaug M, Lancelotta R, Van Oorsouw K, Kuypers K, Mason N, Rak J, et al. A single inhalation of vapor from dried toad secretion containing 5methoxy-N, N-dimethyltryptamine (5-MeO-DMT) in a naturalistic setting is related to sustained enhancement of satisfaction with life, mindfulnessrelated capacities, and a decrement of psychopathological symptoms. Psychopharmacology. (2019) 236:2653-66. doi: 10.1007/s00213-019-0 5236-w

90. Brachman RA, Mcgowan JC, Perusini JN, Lim SC, Pham TH, Faye C, et al. Ketamine as a prophylactic against stress-induced depressive-like behavior. Biol Psychiatry. (2016) 79:776-86.

91. Frecska E, Móré CE, Vargha A, Luna LE. Enhancement of creative expression and entoptic phenomena as after-effects of repeated ayahuasca ceremonies. $J$ Psychoactive Drugs. (2012) 44:191-9. doi: 10.1080/02791072.2012.703099

92. Noorani T, Garcia-Romeu A, Swift TC, Griffiths RR, Johnson MW. Psychedelic therapy for smoking cessation: qualitative analysis of participant accounts. J Psychopharmacol. (2018) 32:756-69.

93. Watts R, Day C, Krzanowski J, Nutt D, Carhart-Harris R. Patients' accounts of increased "connectedness" and "acceptance" after psilocybin for treatment-resistant depression. J Hum Psychol. (2017) 57:520-64. doi: 10.1177/0022167817709585

94. Catlow BJ, Song S, Paredes DA, Kirstein CL, Sanchez-Ramos J. Effects of psilocybin on hippocampal neurogenesis and extinction of trace fear conditioning. Exp Brain Res. (2013) 228:481-91. doi: 10.1007/s00221-013-3579-0

95. Erritzoe D, Roseman L, Nour M, Maclean K, Kaelen M, Nutt D, et al. Effects of psilocybin therapy on personality structure. Acta Psychiatr Scand. (2018) 138:368-78. doi: 10.1111/acps.12904

96. Levin ME, Hildebrandt MJ, Lillis J, Hayes SC. The impact of treatment components suggested by the psychological flexibility model: a metaanalysis of laboratory-based component studies. Behav Ther. (2012) 43:74156. doi: 10.1016/j.beth.2012.05.003

97. Mccracken LM, Velleman SC. Psychological flexibility in adults with chronic pain: a study of acceptance, mindfulness, and values-based action in primary care. Pain. (2010) 148:141-7. doi: 10.1016/j.pain.2009.10.034

98. Moore A, Malinowski P. Meditation, mindfulness and cognitive flexibility. Conscious Cogn. (2009) 18:176-86. doi: 10.1016/j.concog.2008.12.008

99. Lebuda I, Zabelina DL, Karwowski M. Mind full of ideas: a metaanalysis of the mindfulness-creativity link. Pers Individ Dif. (2016) 93:226. doi: 10.1016/j.paid.2015.09.040

100. Tomac MM. The Influence of Mindfulness on Resilience in Context of Attachment Style, Affect Regulation, and Self-Esteem. Washington, DC: Walden University (2011).

101. Coffey KA, Hartman M, Fredrickson BL. Deconstructing mindfulness and constructing mental health: understanding mindfulness and its mechanisms of action. Mindfulness. (2010) 1:235-53. doi: 10.1007/s12671-010-0033-2

102. Waugh CE, Thompson RJ, Gotlib IH. Flexible emotional responsiveness in trait resilience. Emotion. (2011) 11:1059.

103. Harvey JA. Role of the serotonin 5-HT2A receptor in learning. Learn Mem. (2003) 10:355-62. doi: 10.1101/lm.60803
104. Nour MM, Evans L, Nutt D, Carhart-Harris RL. Ego-dissolution and psychedelics: validation of the ego-dissolution inventory (EDI). Front Hum Neurosci. (2016) 10:269. doi: 10.3389/fnhum.2016.00269

105. Timmermann C, Roseman L, Williams L, Erritzoe D, Martial C, Cassol H, et al. DMT models the near-death experience. Front Psychol. (2018) 9:1424. doi: 10.3389/fpsyg.2018.01424

106. Roseman L, Haijen E, Idialu-Ikato K, Kaelen M, Watts R, CarhartHarris R. Emotional breakthrough and psychedelics: validation of the Emotional Breakthrough Inventory. J Psychopharmacol. (2019) 33:107687. doi: 10.1177/0269881119855974

107. Breeksema JJ, Niemeijer AR, Krediet E, Vermetten E, Schoevers RA. Psychedelic treatments for psychiatric disorders: a systematic review and thematic synthesis of patient experiences in qualitative studies. CNS Drugs. (2020) 34:925-46. doi: 10.1007/s40263-020-00748-y

108. Milliere R. Looking for the self: phenomenology, neurophysiology and philosophical significance of drug-induced ego dissolution. Front Hum Neurosci. (2017) 11:245. doi: 10.3389/fnhum.2017.00245

109. Griffiths RR, Johnson MW, Richards WA, Richards BD, Mccann U, Jesse R. Psilocybin occasioned mystical-type experiences: immediate and persisting dose-related effects. Psychopharmacology. (2011) 218:64965. doi: 10.1007/s00213-011-2358-5

110. Ly C, Greb AC, Cameron LP, Wong JM, Barragan EV, Wilson PC, et al. Psychedelics promote structural and functional neural plasticity. Cell Rep. (2018) 23:3170-82. doi: 10.1016/j.celrep.2018.05.022

111. Kowiański P, Lietzau G, Czuba E, Waśkow M, Steliga A, Moryś J. BDNF: a key factor with multipotent impact on brain signaling and synaptic plasticity. Cell Mol Neurobiol. (2018) 38:579-93. doi: 10.1007/s10571-017-0510-4

112. Spriggs M, Cadwallader C, Hamm J, Tippett L, Kirk I. Age-related alterations in human neocortical plasticity. Brain Res Bull. (2017) 130:539. doi: 10.1016/j.brainresbull.2016.12.015

113. Hayes SC, Strosahl KD, Wilson KG. Acceptance and Commitment Therapy: The Process and Practice of Mindful change. New York, NY: Guilford Press (2011).

114. Rolffs JL, Rogge RD, Wilson KG. Disentangling components of flexibility via the hexaflex model: development and validation of the multidimensional psychological flexibility inventory (MPFI). Assessment. (2018) 25:45882. doi: $10.1177 / 1073191116645905$

115. Luoma JB, Sabucedo P, Eriksson J, Gates N, Pilecki BC. Toward a contextual psychedelic-assisted therapy: perspectives from acceptance and commitment therapy and contextual behavioral science. J Context Behav Sci. (2019) 14:136-45. doi: 10.1016/j.jcbs.2019.10.003

116. Levin ME, Maclane C, Daflos S, Seeley JR, Hayes SC, Biglan A, et al. Examining psychological inflexibility as a transdiagnostic process across psychological disorders. J Context Behav Sci. (2014) 3:15563. doi: $10.1016 /$ j.jcbs.2014.06.003

117. Meiran N, Diamond GM, Toder D, Nemets B. Cognitive rigidity in unipolar depression and obsessive compulsive disorder: examination of task switching, stroop, working memory updating and post-conflict adaptation. Psychiatry Res. (2011) 185:149-56. doi: 10.1016/j.psychres.2010.04.044

118. Fisher AJ, Newman MG. Reductions in the diurnal rigidity of anxiety predict treatment outcome in cognitive behavioral therapy for generalized anxiety disorder. Behav Res Ther. (2016) 79:46-55. doi: 10.1016/j.brat.2016.02.006

119. Nichols DE, Johnson MW, Nichols CD. Psychedelics as medicines: an emerging new paradigm. Clin Pharmacol Ther. (2017) 101:20919. doi: $10.1002 /$ cpt.557

120. Lafrance A, Loizaga-Velder A, Fletcher J, Renelli M, Files N, Tupper KW. Nourishing the spirit: exploratory research on ayahuasca experiences along the continuum of recovery from eating disorders. J Psychoactive Drugs. (2017) 49:427-35. doi: 10.1080/02791072.2017.1361559

121. Hayes SC. A Liberated Mind: How to Pivot Toward What Matters. New York, NY: Avery (2019).

122. Bond FW, Hayes SC, Baer RA, Carpenter KM, Guenole N, Orcutt $\mathrm{HK}$, et al. Preliminary psychometric properties of the acceptance and action questionnaire-II: a revised measure of psychological inflexibility and experiential avoidance. Behav Ther. (2011) 42:676-88. doi: 10.1016/j.beth.2011.03.007

123. Kashdan TB, Rottenberg J. Psychological flexibility as a fundamental aspect of health. Clin Psychol Rev. (2010) 30:865-78. doi: 10.1016/j.cpr.2010.03.001 
124. Fledderus M, Bohlmeijer ET, Smit F, Westerhof GJ. Mental health promotion as a new goal in public mental health care: A randomized controlled trial of an intervention enhancing psychological flexibility. Am J Public Health. (2010) 100:2372. doi: 10.2105/AJPH.2010.1 96196

125. Hayes SC. Acceptance and commitment therapy, relational frame theory, and the third wave of behavioral and cognitive therapies. Behav Ther. (2004) 35:639-65. doi: 10.1016/S0005-7894(04)80013-3

126. Hofmann SG, Sawyer AT, Fang A. The empirical status of the "new wave" of cognitive behavioral therapy. Psychiatr Clin. (2010) 33:70110. doi: $10.1016 /$ j.psc.2010.04.006

127. Hanh N. The Miracle of Mindfulness: The Classic Guide to Meditation by the World's Most Revered Master. London: Ebury Digital (2017).

128. Wright R. Why Buddhism Is True: The Science and Philosophy of Meditation and Enlightenment. New York, NY: Simon and Schuster (2017).

129. Ciarrochi J, Bilich L, Godsell C. Psychological flexibility as a mechanism of change in acceptance and commitment therapy. In: Baer RA, editor. Assessing Mindfulness and Acceptance Processes in Clients: Illuminating the Theory and Practice of Change. Oakland: Context Press/New Harbinger Publications (2010). p. 51-75.

130. Kočárová R. Účinné faktory rituálního uŽití ayahuascy pri léčbě závislostív psychoterapeutickém kontextu (Master). Masaryk University (2016).

131. Carhart-Harris RL, Erritzoe D, Haijen E, Kaelen M, Watts R. Psychedelics and connectedness. Psychopharmacology. (2018) 235:547-50. doi: 10.1007/s00213-017-4701-y

132. Davis AK, Barrett FS, Griffiths RR. Psychological flexibility mediates the relations between acute psychedelic effects and subjective decreases in depression and anxiety. J Context Behav Sci. (2019) 15:39-45. doi: 10.1016/j.jcbs.2019.11.004

133. Walsh Z, Thiessen MS. Psychedelics and the new behaviourism: considering the integration of third-wave behaviour therapies with psychedelic-assisted therapy. Int Rev Psychiatry. (2018) 30:343-9. doi: 10.1080/09540261.2018.1474088

134. Sloshower J, Guss J, Krause R, Wallace RM, Williams MT, Reed S, et al. Psilocybin-assisted therapy of major depressive disorder using acceptance and commitment therapy as a therapeutic frame. J Context Behav Sci. (2020) 15:12-9. doi: 10.1016/j.jcbs.2019.11.002

135. Stemme A, Deco G, Busch A. The neuronal dynamics underlying cognitive flexibility in set shifting tasks. J Comput Neurosci. (2007) 23:313. doi: 10.1007/s10827-007-0034-x

136. Tchanturia K, Davies H, Roberts M, Harrison A, Nakazato M, Schmidt $\mathrm{U}$, et al. Poor cognitive flexibility in eating disorders: examining the evidence using the Wisconsin Card Sorting Task. PLoS ONE. (2012) 7:e28331. doi: 10.1371/journal.pone.0028331

137. Kanen JW, Ersche KD, Fineberg NA, Robbins TW, Cardinal RN. Computational modelling reveals contrasting effects on reinforcement learning and cognitive flexibility in stimulant use disorder and obsessive-compulsive disorder: remediating effects of dopaminergic D2/3 receptor agents. Psychopharmacology. (2019) 236:2337-58. doi: 10.1007/s00213-019-05325-w

138. Davis RN, Nolen-Hoeksema S. Cognitive inflexibility among ruminators and nonruminators. Cognit Ther Res. (2000) 24:699-711. doi: 10.1023/A:1005591412406

139. Tchanturia K, Harrison A, Davies H, Roberts M, Oldershaw A, Nakazato M, et al. Cognitive flexibility and clinical severity in eating disorders. PLOS ONE. (2011) 6:e20462. doi: 10.1371/journal.pone.0020462

140. Lee JK, Orsillo SM. Investigating cognitive flexibility as a potential mechanism of mindfulness in generalized anxiety disorder. J Behav Ther Exp Psychiatry. (2014) 45:208-16. doi: 10.1016/j.jbtep.2013.10.008

141. Van Eylen L, Boets B, Steyaert J, Evers K, Wagemans J, Noens I. Cognitive flexibility in autism spectrum disorder: explaining the inconsistencies? Res Autism Spectr Disord. (2011) 5:1390-401. doi: 10.1016/j.rasd.2011.01.025

142. Hirt ER, Devers EE, Mccrea SM. I want to be creative: exploring the role of hedonic contingency theory in the positive mood-cognitive flexibility link. $J$ Pers Soc Psychol. (2008) 94:214. doi: 10.1037/0022-3514.94.2.94.2.214

143. Pokorny T, Duerler P, Seifritz E, Vollenweider FX, Preller KH. LSD acutely impairs working memory, executive functions, and cognitive flexibility, but not risk-based decision-making. Psychol Med. (2019) 50:225564. doi: $10.1017 /$ S0033291719002393

144. Kanen J, Robbins T, Carhart-Harris R, Den Ouden H. Effects of lysergic acid dyethylamide (LSD) on probabilistic reversal learning in humans. In: Summer Meeting of the British Association For Psychopharmacology (2019).

145. Nichols DE. Psychedelics. Pharmacol Rev. (2016) 68:264355. doi: 10.1124/pr.115.011478

146. Puglisi-Allegra S, Andolina D. Serotonin and stress coping. Behav Brain Res. (2015) 277:58-67. doi: 10.1016/j.bbr.2014.07.052

147. Audenaert K, Van Laere K, Dumont F, Vervaet M, Goethals I, Slegers G, et al. Decreased 5-HT2a receptor binding in patients with anorexia nervosa. $J$ Nuclear Med. (2003) 44:163-9.

148. Bailer UF, Price JC, Meltzer CC, Mathis CA, Frank GK, Weissfeld L, et al. Altered 5-HT 2A receptor binding after recovery from bulimia-type anorexia nervosa: relationships to harm avoidance and drive for thinness. Neuropsychopharmacology. (2004) 29:1143-55. doi: 10.1038/sj.npp.1300430

149. Frank GK, Kaye WH, Meltzer CC, Price JC, Greer P, Mcconaha C, et al. Reduced 5-HT2A receptor binding after recovery from anorexia nervosa. Biol Psychiatry. (2002) 52:896-906. doi: 10.1016/S0006-3223(02)01378-1

150. Tchanturia K, Anderluh MB, Morris RG, Rabe-Hesketh S, Collier DA, Sanchez P, et al. Cognitive flexibility in anorexia nervosa and bulimia nervosa. J Int Neuropsychol Soc. (2004) 10:513. doi: $10.1017 /$ S1355617704104086

151. Horacek J, Bubenikova-Valesova V, Kopecek M, Palenicek T, Dockery C, Mohr P, et al. Mechanism of action of atypical antipsychotic drugs and the neurobiology of schizophrenia. CNS Drugs. (2006) 20:389-409. doi: 10.2165/00023210-20062005000004

152. Cummings J, Isaacson S, Mills R, Williams H, Chi-Burris K, Corbett A, et al. Pimavanserin for patients with Parkinson's disease psychosis: a randomised, placebo-controlled phase 3 trial. Lancet. (2014) 383:53340. doi: 10.1016/S0140-6736(13)62106-6

153. Ballard C, Creese B, Gatt A, Doherty P, Francis P, Whitfield D, et al. Identifying Novel candidates for re-purposing as potential therapeutic agents for Alzheimer's disease. bioRxiv. (2019) 25:159-170. doi: 10.1101/622308

154. Garay RP, Bourin M, De Paillette E, Samalin L, Hameg A, Llorca P-M. Potential serotonergic agents for the treatment of schizophrenia. Expert Opin Investig Drugs. (2016) 25:159-70. doi: 10.1517/13543784.2016.1121995

155. Carhart-Harris R, Nutt D. Serotonin and brain function: a tale of two receptors. J Psychopharmacol. (2017) 31:1091120. doi: $10.1177 / 0269881117725915$

156. Bayne T, Carter O. Dimensions of consciousness and the psychedelic state. Neurosci Conscious. (2018) 2018:niy008. doi: 10.1093/nc/niy008

157. Lieberman JN. Playfulness and divergent thinking: an investigation of their relationship at the kindergarten level. J Genet Psychol. (1965) 107:21924. doi: 10.1080/00221325.1965.10533661

158. Dreu CKD, Nijstad BA, Baas M. Behavioral activation links to creativity because of increased cognitive flexibility. Soc Psychol Personal Sci. (2011) 2:72-80. doi: 10.1177/1948550610381789

159. Hayes S. A Liberated Mind: The essential guide to ACT. London: Random House (2019).

160. Kenett YN, Levy O, Kenett DY, Stanley HE, Faust M, Havlin S. Flexibility of thought in high creative individuals represented by percolation analysis. Proc Natl Acad Sci. (2018) 115:867-72. doi: 10.1073/pnas.1717362115

161. Stein MI. Creativity and culture. J Psychol. (1953) 36:31122. doi: $10.1080 / 00223980.1953 .9712897$

162. Forgeard MJ, Elstein JG. Advancing the clinical science of creativity. Front Psychol. (2014) 5:613. doi: 10.3389/fpsyg.2014.00613

163. Blake A, Palmisano S. Divergent thinking influences the perception of ambiguous visual illusions. Perception. (2021) 50:418-37. doi: 10.1177/03010066211000192

164. Harman WW, Mckim RH, Mogar RE, Fadiman J, Stolaroff MJ. Psychedelic agents in creative problem-solving: a pilot study. Psychol Rep. (1966) 19:21127. doi: $10.2466 /$ pro.1966.19.1.211

165. Sweat NW, Bates LW, Hendricks PS. The associations of naturalistic classic psychedelic use, mystical experience, and creative problem solving. $J$ Psychoactive Drugs. (2016) 48:344-50. doi: 10.1080/02791072.2016.1234090 
166. Kuypers K, Riba J, De La Fuente Revenga M, Barker S, Theunissen E, Ramaekers J. Ayahuasca enhances creative divergent thinking while decreasing conventional convergent thinking. Psychopharmacology. (2016) 233:3395-403. doi: 10.1007/s00213-016-4377-8

167. Germann CB. 5-methoxy-N, N-dimethyltryptamine: an ego-dissolving endogenous neurochemical catalyst of creativity. Act Nerv Super. (2019) 61:170-216. doi: 10.1007/s41470-019-00063-y

168. Sessa B. Is it time to revisit the role of psychedelic drugs in enhancing human creativity? J Psychopharmacol. (2008) 22:821-7. doi: 10.1177/0269881108091597

169. Baggott MJ. Psychedelics and creativity: a review of the quantitative literature. PeerJ PrePrints. (2015) 3:e1202ve1201. doi: 10.7287/peerj.preprints.1202v1

170. Girn M, Mills C, Roseman L, Carhart-Harris RL, Christoff K. Updating the dynamic framework of thought: Creativity and psychedelics. Neuroimage. (2020) 213:116726. doi: 10.1016/j.neuroimage.2020.116726

171. Mccrae RR. Creativity, divergent thinking, and openness to experience. J Pers Soc Psychol. (1987) 52:1258. doi: 10.1037/0022-3514.52.6.1258

172. Chen X, He J, Fan X. Relationships between openness to experience, cognitive flexibility, self-esteem, and creativity among bilingual college students in the US. Int J Bilingual Educ Bilingualism. (2019) 113. doi: $10.1080 / 13670050.2019 .1688247$

173. Costa PT, McCrae RR. The revised NEO personality inventory (NEO-PI-R). The SAGE Handbook Pers Theory Assess. (2008) 2:179-98. doi: 10.4135/9781849200479.n9

174. Carhart-Harris RL, Kaelen M, Bolstridge M, Williams T, Williams L, Underwood $\mathrm{R}$, et al. The paradoxical psychological effects of lysergic acid diethylamide (LSD). Psychol Med. (2016) 46:1379-90. doi: 10.1017/S0033291715002901

175. Erritzoe D, Smith J, Fisher PM, Carhart-Harris R, Frokjaer VG, Knudsen GM. Recreational use of psychedelics is associated with elevated personality trait openness: exploration of associations with brain serotonin markers. J Psychopharmacol. (2019) 33:1068-75. doi: 10.1177/0269881119 827891

176. Wagner MT, Mithoefer MC, Mithoefer AT, Macaulay RK, Jerome L, Yazar-Klosinski B, et al. Therapeutic effect of increased openness: Investigating mechanism of action in MDMA-assisted psychotherapy. J Psychopharmacol. (2017) 31:967-74. doi: 10.1177/02698811177 11712

177. Eldesouky L. Openness to experience and health: a review of the literature. Yale Rev Undergrad Res Psychol. (2012) 5:24-42.

178. Bishop SR, Lau M, Shapiro S, Carlson L, Anderson ND, Carmody J, et al. Mindfulness: a proposed operational definition. Clin Psychol: Sci Pract. (2004) 11:230-41. doi: 10.1093/clipsy.bph077

179. Baer RA, Smith GT, Lykins E, Button D, Krietemeyer J, Sauer S, et al. Construct validity of the five facet mindfulness questionnaire in meditating and nonmeditating samples. Assessment. (2008) 15:32942. doi: $10.1177 / 1073191107313003$

180. Hayes SC, Law S, Malady M, Zhu Z, Bai X. The centrality of sense of self in psychological flexibility processes: what the neurobiological and psychological correlates of psychedelics suggest. J Context Behav Sci. (2019) 15:30-8. doi: 10.1016/j.jcbs.2019.11.005

181. Speth J, Speth C, Kaelen M, Schloerscheidt AM, Feilding A, Nutt DJ, et al. Decreased mental time travel to the past correlates with default-mode network disintegration under lysergic acid diethylamide. J Psychopharmacol. (2016) 30:344-53. doi: $10.1177 / 0269881116628430$

182. Roseman L, Nutt DJ, Carhart-Harris RL. Quality of acute psychedelic experience predicts therapeutic efficacy of psilocybin for treatment-resistant depression. Front Pharmacol. (2018) 8:974. doi: 10.3389/fphar.2017.00974

183. Haijen ECHM, Kaelen M, Roseman L, Timmermann C, Russ S, Nutt D, et al. Predicting responses to psychedelics: a prospective study. Front Pharmacol. (2018) 9:897. doi: 10.3389/fphar.2018.00897

184. Schmid Y, Liechti ME. Long-lasting subjective effects of LSD in normal subjects. Psychopharmacology. (2018) 235:53545. doi: 10.1007/s00213-017-4733-3

185. Lebedev AV, Kaelen M, Lövdén M, Nilsson J, Feilding A, Nutt DJ, et al. LSDinduced entropic brain activity predicts subsequent personality change. Hum Brain Mapp. (2016) 37:3203-13. doi: 10.1002/hbm.23234
186. Lifshitz M, Van Elk M, Luhrmann T. Absorption and spiritual experience: A review of evidence and potential mechanisms. Conscious Cogn. (2019) 73:102760. doi: 10.1016/j.concog.2019.05.008

187. Maclean KA, Leoutsakos JMS, Johnson MW, Griffiths RR. Factor analysis of the mystical experience questionnaire: a study of experiences occasioned by the hallucinogen psilocybin. J Sci Study Relig. (2012) 51:72137. doi: 10.1111/j.1468-5906.2012.01685.x

188. Lukoff D, Lu F, Turner R. From spiritual emergency to spiritual problem: the transpersonal roots of the new DSM-IV category. J Hum Psychol. (1998) 38:21-50. doi: 10.1177/00221678980382003

189. Stace WT. Mysticism and Philosophy. Philadelphia, PA: J. B. Lippincott (1960).

190. Petri G, Expert P, Turkheimer F, Carhart-Harris R, Nutt D, Hellyer PJ, et al. Homological scaffolds of brain functional networks. J R Soc Interface. (2014) 11:20140873. doi: 10.1098/rsif.2014.0873

191. Millière R, Carhart-Harris RL, Roseman L, Trautwein F-M, BerkovichOhana A. Psychedelics, meditation, and self-consciousness. Front Psychol. (2018) 9:1475. doi: 10.3389/fpsyg.2018.01475

192. Nielson EM, May DG, Forcehimes AA, Bogenschutz MP. The psychedelic debriefing in alcohol dependence treatment: illustrating key change phenomena through qualitative content analysis of clinical sessions. Front Pharmacol. (2018) 9:132. doi: 10.3389/fphar.2018.00132

193. Tagliazucchi E, Roseman L, Kaelen M, Orban C, Muthukumaraswamy $\mathrm{SD}$, Murphy $\mathrm{K}$, et al. Increased global functional connectivity correlates with LSD-induced ego dissolution. Curr Biol. (2016) 26:1043-50. doi: 10.1016/j.cub.2016.02.010

194. Carhart-Harris RL, Muthukumaraswamy S, Roseman L, Kaelen M, Droog W, Murphy K, et al. Neural correlates of the LSD experience revealed by multimodal neuroimaging. Proc Natl Acad Sci USA. (2016) 113:48538. doi: 10.1073/pnas. 1518377113

195. Hanh TN. The Heart of Buddha's Teaching. London: Random House (2008).

196. Edgerton F. The Bhagavad Gita. Cambridge: Harvard University Press (1972)

197. Girn M, Roseman L, Bernhardt B, Smallwood J, Carhart-Harris RL, Spreng N. LSD flattens the functional hierarchy of the human brain. bioRxiv. (2020). doi: $10.1101 / 2020.05 .01 .072314$

198. Atasoy S, Roseman L, Kaelen M, Kringelbach ML, Deco G, CarhartHarris RL. Connectome-harmonic decomposition of human brain activity reveals dynamical repertoire re-organization under LSD. Sci Rep. (2017) 7:17661. doi: 10.1038/s41598-017-17546-0

199. Tagliazucchi E, Carhart-Harris R, Leech R, Nutt D, Chialvo DR. Enhanced repertoire of brain dynamical states during the psychedelic experience. Hum Brain Mapp. (2014) 35:5442-56. doi: 10.1002/hbm.22562

200. Atasoy S, Vohryzek J, Deco G, Carhart-Harris RL, Kringelbach ML. Common neural signatures of psychedelics: frequencyspecific energy changes and repertoire expansion revealed using connectome-harmonic decomposition. Prog Brain Res. (2018) 242:97-120. doi: 10.1016/bs.pbr.2018.08.009

201. Lord LD, Expert P, Atasoy S, Roseman L, Rapuano K, Lambiotte $\mathrm{R}$, et al. Dynamical exploration of the repertoire of brain networks at rest is modulated by psilocybin. Neuroimage. (2019) 199:127-42. doi: 10.1016/j.neuroimage.2019.05.060

202. Roseman L, Leech R, Feilding A, Nutt DJ, Carhart-Harris RL. The effects of psilocybin and MDMA on between-network resting state functional connectivity in healthy volunteers. Front Hum Neurosci. (2014) 8:204. doi: $10.3389 /$ fnhum.2014.00204

203. Pittenger C, Duman RS. Stress, depression, and neuroplasticity: a convergence of mechanisms. Neuropsychopharmacology. (2008) 33:88. doi: 10.1038/sj.npp.1301574

204. Cramer SC, Sur M, Dobkin BH, O’brien C, Sanger TD, Trojanowski JQ, et al. Harnessing neuroplasticity for clinical applications. Brain. (2011) 134:1591-609. doi: 10.1093/brain/awr039

205. Doidge N. The Brain That Changes Itself: Stories of Personal Triumph From the Frontiers of Brain Science. Penguin (2007).

206. Stam CJ. Modern network science of neurological disorders. Nat Rev Neurosci. (2014) 15:683. doi: 10.1038/nrn3801

207. Lydon-Staley D, Kuehner C, Zamoscik V, Huffziger S, Kirsch P, Bassett D. Repetitive negative thinking in daily life and functional connectivity among 
default mode, fronto-parietal, and salience networks. Transl Psychiatry. (2019) 9:1-12. doi: 10.1038/s41398-019-0560-0

208. Zheng H, Li F, Bo Q, Li X, Yao L, Yao Z, et al. The dynamic characteristics of the anterior cingulate cortex in resting-state fMRI of patients with depression. J Affect Disord. (2018) 227:391-7. doi: 10.1016/j.jad.2017.11.026

209. Kolassa I-T, Elbert T. Structural and functional neuroplasticity in relation to traumatic stress. Curr Dir Psychol Sci. (2007) 16:3215. doi: 10.1111/j.1467-8721.2007.00529.x

210. Zanos P, Gould TD. Mechanisms of ketamine action as an antidepressant. Mol Psychiatry. (2018) 23:801. doi: 10.1038/mp.2017.255

211. Cavus I, Duman RS. Influence of estradiol, stress, and 5-HT2A agonist treatment on brain-derived neurotrophic factor expression in female rats. Biol Psychiatry. (2003) 54:59-69. doi: 10.1016/S0006-3223(03)0 0236-1

212. Olson DE. Psychoplastogens: a promising class of plasticitypromoting neurotherapeutics. $J$ Exp Neurosci. (2018) 12:1179069518800508. doi: 10.1177/1179069518800508

213. Jefsen $\mathrm{OH}$, Elfving B, Wegener G, Müller HK. Transcriptional regulation in the rat prefrontal cortex and hippocampus after a single administration of psilocybin. J Psychopharmacol. (2020) 35:483-93. doi: 10.1177/0269881120959614

214. Harmer CJ, Duman RS, Cowen PJ. How do antidepressants work? New perspectives for refining future treatment approaches. Lancet Psychiatry. (2017) 4:409-18. doi: 10.1016/S2215-0366(17)30015-9

215. Hölzel BK, Lazar SW, Gard T, Schuman-Olivier Z, Vago DR, Ott U. How does mindfulness meditation work? Proposing mechanisms of action from a conceptual and neural perspective. Perspect Psychol Sci. (2011) 6:53759. doi: 10.1177/1745691611419671

216. Sos P, Klirova M, Novak T, Kohutova B, Horacek J, Palenicek T. Relationship of ketamine's antidepressant and psychotomimetic effects in unipolar depression. Neuroendocrinol Let. (2013) 34:287-93.

217. Luckenbaugh DA, Niciu MJ, Ionescu DF, Nolan NM, Richards EM, Brutsche NE, et al. Do the dissociative side effects of ketamine mediate its antidepressant effects? J Affect Disord. (2014) 159:5661. doi: 10.1016/j.jad.2014.02.017

218. Olson DE. The Subjective effects of psychedelics may not be necessary for their enduring therapeutic effects. ACS Pharmacol Trans Sci. (2020) 4:563-7. doi: 10.1021/acsptsci.0c00192

219. Vaidya VA, Marek GJ, Aghajanian GK, Duman RS. 5-HT2A receptormediated regulation of brain-derived neurotrophic factor mRNA in the hippocampus and the neocortex. J Neurosci. (1997) 17:278595. doi: 10.1523/JNEUROSCI.17-08-02785.1997

220. Vaidya V, Castro M, Pei Q, Sprakes M, Grahame-Smith D. Influence of thyroid hormone on 5-HT1A and 5-HT2A receptor-mediated regulation of hippocampal BDNF mRNA expression. Neuropharmacology. (2001) 40:4856. doi: 10.1016/S0028-3908(00)00094-0

221. Morales-García JA, De La Fuente Revenga M, Alonso-Gil S, RodríguezFranco MI, Feilding A, Perez-Castillo A, et al. The alkaloids of Banisteriopsis caapi, the plant source of the Amazonian hallucinogen Ayahuasca, stimulate adult neurogenesis in vitro. Sci Rep. (2017) 7:5309. doi: 10.1038/s41598-017-05407-9

222. Xing L, Kalebic N, Namba T, Vaid S, Wimberger P, Huttner WB. Serotonin receptor $2 \mathrm{~A}$ activation promotes evolutionarily relevant basal progenitor proliferation in the developing neocortex. Neuron. (2020) 108:111329.e6. doi: 10.1016/j.neuron.2020.09.034

223. Vicenzi S, Foa L, Gasperini RJ. Serotonin functions as a bidirectional guidance molecule regulating growth cone motility. Cell Mol Life Sci. (2021) 78:2247-62. doi: 10.1007/s00018-020-03628-2

224. Dewitt TJ, Sih A, Wilson DS. Costs and limits of phenotypic plasticity. Trends Ecol Evol. (1998) 13:77-81. doi: 10.1016/S0169-5347(97)01274-3

225. Branchi I. The double edged sword of neural plasticity: increasing serotonin levels leads to both greater vulnerability to depression and improved capacity to recover. Psychoneuroendocrinology. (2011) 36:33951. doi: 10.1016/j.psyneuen.2010.08.011

226. Schartner MM, Carhart-Harris RL, Barrett AB, Seth AK, Muthukumaraswamy SD. Increased spontaneous MEG signal diversity for psychoactive doses of ketamine, LSD and psilocybin. Sci Rep. (2017) 7:46421. doi: 10.1038/srep46421
227. Carhart-Harris RL, Erritzoe D, Williams T, Stone JM, Reed LJ, Colasanti A, et al. Neural correlates of the psychedelic state as determined by fMRI studies with psilocybin. Proc Natl Acad Sci. (2012) 109:213843. doi: 10.1073/pnas.1119598109

228. Carhart-Harris RL, Leech R, Hellyer PJ, Shanahan M, Feilding A, Tagliazucchi E, et al. The entropic brain: a theory of conscious states informed by neuroimaging research with psychedelic drugs. Front Hum Neurosci. (2014) 8:20. doi: 10.3389/fnhum.201 4.00020

229. Nutt D, Erritzoe D, Carhart-Harris R. Psychedelic psychiatry's brave new world. Cell. (2020) 181:24-8. doi: 10.1016/j.cell.2020.03.020

230. Carhart-Harris RL. The entropic brain-revisited. Neuropharmacology. (2018) 142:167-78. doi: 10.1016/j.neuropharm.2018.03.010

231. Carhart-Harris RL, Roseman L, Bolstridge M, Demetriou L, Pannekoek JN, Wall MB, et al. Psilocybin for treatment-resistant depression: fMRI-measured brain mechanisms. Sci Rep. (2017) 7:13187. doi: 10.1038/s41598-017-13282-7

232. Beliveau V, Ganz M, Feng L, Ozenne B, Højgaard L, Fisher PM, et al. A highresolution in vivo atlas of the human brain's serotonin system. $J$ Neurosci. (2017) 37:120-8. doi: 10.1523/JNEUROSCI.2830-16.2016

233. Van Laarhoven PJ, Aarts EH. Simulated Annealing. Simulated Annealing: Theory and Applications. Heidelberg: Springer Netherlands (1987).

234. Olthof M, Hasselman F, Strunk G, Aas B, Schiepek G, Lichtwarck-Aschoff A. Destabilization in self-ratings of the psychotherapeutic process is associated with better treatment outcome in patients with mood disorders. Psychother Res. (2019) 30:520-31. doi: 10.1080/10503307.2019.1633484

235. Crown S. Contraindications and dangers of psychotherapy. Br J Psychiatry. (1983) 143:436-41. doi: 10.1192/bjp.143.5.436

236. Lloyd V. The Jarisch-Herxheimer reaction. Br J Venereal Dis. (1945) 21:42. doi: 10.1136/sti.21.1.42

237. Russ SL, Carhart-Harris R, Maruyama G, Elliott M. Replication and extension of a model predicting response to psilocybin. Psychopharmacology. (2019) 236:3221-30. doi: 10.1007/s00213-019-05279-Z

238. Strogatz SH. Nonlinear Dynamics and Chaos With Student Solutions Manual: With Applications to Physics, Biology, Chemistry, and Engineering. CRC Press (2018).

239. Grencavage LM, Norcross JC. Where are the commonalities among the therapeutic common factors? Prof Psychol Res Pract. (1990) 21:372. doi: 10.1037/0735-7028.21.5.372

240. Alamia A, Timmermann C, Vanrullen R, Carhart-Harris RL. DMT alters cortical travelling waves. Elife. (2020) e59784. doi: 10.7554/eLife.59784

241. Cameron JL, Eagleson KL, Fox NA, Hensch TK, Levitt P. Social origins of developmental risk for mental and physical illness. J Neurosci. (2017) 37:10783-91. doi: 10.1523/JNEUROSCI.1822-17.2017

242. Ismail FY, Fatemi A, Johnston MV. Cerebral plasticity: windows of opportunity in the developing brain. Eur J Paediatr Neurol. (2017) 21:2348. doi: 10.1016/j.ejpn.2016.07.007

243. Jayawickreme E, Blackie LE. Post-traumatic growth as positive personality change: evidence, controversies and future directions. Eur J Pers. (2014) 28:312-31. doi: 10.1002/per.1963

244. Boykin DM, Anyanwu J, Calvin K, Orcutt HK. The moderating effect of psychological flexibility on event centrality in determining trauma outcomes. Psychol Trauma Theory Res Pract Policy. (2019) 12:1939. doi: $10.1037 /$ tra0000490

245. Buckner RL, Krienen FM. The evolution of distributed association networks in the human brain. Trends Cogn Sci. (2013) 17:64865. doi: 10.1016/j.tics.2013.09.017

246. Rilling JK. Comparative primate neuroimaging: insights into human brain evolution. Trends Cogn Sci. (2014) 18:46-55. doi: 10.1016/j.tics.2013.09.013

247. Baldassano C, Chen J, Zadbood A, Pillow JW, Hasson U, Norman KA. Discovering Event structure in continuous narrative perception and memory. Neuron. (2017) 95:709-21.e5. doi: 10.1016/j.neuron.2017.06.041

248. Huth AG, De Heer WA, Griffiths TL, Theunissen FE, Gallant JL. Natural speech reveals the semantic maps that tile human cerebral cortex. Nature. (2016) 532:453-8. doi: 10.1038/nature17637

249. Sepulcre J, Liu H, Talukdar T, Martincorena I, Yeo BT, Buckner RL. The organization of local and distant functional connectivity in the human brain. PLoS Comput Biol. (2010) 6:e1000808. doi: 10.1371/journal.pcbi.1000808 
250. Margulies DS, Ghosh SS, Goulas A, Falkiewicz M, Huntenburg JM, Langs $\mathrm{G}$, et al. Situating the default-mode network along a principal gradient of macroscale cortical organization. Proc Natl Acad Sci USA. (2016) 113:125749. doi: 10.1073/pnas.1608282113

251. Krienen FM, Yeo BT, Ge T, Buckner RL, Sherwood CC. Transcriptional profiles of supragranular-enriched genes associate with corticocortical network architecture in the human brain. Proc Natl Acad Sci USA. (2016) 113:E469-78. doi: 10.1073/pnas.1510903113

252. Xu T, Nenning KH, Schwartz E, Hong SJ, Vogelstein JT, Goulas A, et al. Cross-species functional alignment reveals evolutionary hierarchy within the connectome. Neuroimage. (2020) 223:117346. doi: 10.1016/j.neuroimage.2020.117346

253. Vaishnavi SN, Vlassenko AG, Rundle MM, Snyder AZ, Mintun MA, Raichle ME. Regional aerobic glycolysis in the human brain. Proc Natl Acad Sci. (2010) 107:17757-62. doi: 10.1073/pnas.10104 59107

254. Vlassenko AG, Vaishnavi SN, Couture L, Sacco D, Shannon BJ, Mach $\mathrm{RH}$, et al. Spatial correlation between brain aerobic glycolysis and amyloid- $\beta$ (A $\beta$ ) deposition. Proc Natl Acad Sci. (2010) 107:177637. doi: 10.1073/pnas.1010461107

255. Yaden DB, Griffiths RR. The subjective effects of psychedelics are necessary for their enduring therapeutic effects. ACS Pharmacol Trans Sci. (2020) 4:568-72. doi: 10.1021/acsptsci.0c00194

256. Szigeti B, Kartner L, Blemings A, Rosas F, Feilding A, Nutt DJ, et al. Selfblinding citizen science to explore psychedelic microdosing. Elife. (2021) 10:e62878. doi: 10.7554/eLife.62878

257. Kaertner L, Steinborn M, Kettner H, Spriggs M, Roseman L, Buchborn T, et al. Positive expectations predict improved mentalhealth outcomes linked to psychedelic microdosing. Sci Rep. (2021) 11:1-11. doi: 10.1038/s41598-021-81446-7

258. Starfield B, Hyde J, Gérvas J, Heath I. The concept of prevention: a good idea gone astray? J Epidemiol Commun Health. (2008) 62:5803. doi: 10.1136/jech.2007.071027

259. Johnson MW, Richards WA, Griffiths RR. Human hallucinogen research: guidelines for safety. J Psychopharmacol. (2008) 22:603-20. doi: 10.1177/02698811080 93587

260. Martinotti G, Santacroce R, Pettorruso M, Montemitro C, Spano $\mathrm{MC}$, Lorusso $\mathrm{M}$, et al. Hallucinogen persisting perception disorder: etiology, clinical features, and therapeutic perspectives. Brain Sci. (2018) 8:47. doi: 10.3390/brainsci8030047

261. Eisner B. Set, setting, and matrix. J Psychoact Drugs. (1997) 29:2136. doi: 10.1080/02791072.1997.10400190

262. Hartogsohn I. Set and setting, psychedelics and the placebo response: an extra-pharmacological perspective on psychopharmacology.
J Psychopharmacol. (2016) 30:1259-67. doi: 10.1177/02698811166 77852

263. Van de Cruys S, Evers K, Van Der Hallen R, Van Eylen L, Boets B, De-Wit L, et al. Precise minds in uncertain worlds: predictive coding in autism. Psychol Rev. (2014) 121:649. doi: 10.1037/a0037665

264. Van de Cruys S, Van Der Hallen R, Wagemans J. Disentangling signal and noise in autism spectrum disorder. Brain Cogn. (2017) 112:7883. doi: 10.1016/j.bandc.2016.08.004

265. Tyndall I, Waldeck D, Pancani L, Whelan R, Roche B, Dawson DL. The acceptance and action questionnaire-II (AAQ-II) as a measure of experiential avoidance: concerns over discriminant validity. J Context Behav Sci. (2018) 12:278-84. doi: 10.1016/j.jcbs.2018.09.005

266. Wolgast M. What does the acceptance and action questionnaire (AAQ-II) really measure? Behav Ther. (2014) 45:8319. doi: 10.1016/j.beth,.2014.07.002

267. Ford I, Norrie J. Pragmatic trials. New Engl J Med. (2016) 375:45463. doi: 10.1056/NEJMra1510059

268. Mullins CD, Vandigo J, Zheng Z, Wicks P. Patient-centeredness in the design of clinical trials. Value Health. (2014) 17:4715. doi: 10.1016/j.jval.2014.02.012

269. Carhart-Harris RL, Wagner AC, Agrawal M, Kettner H, Rosenbaum JF, Gazzaley A, et al. Can pragmatic research, real-world data and digital technologies aid the development of psychedelic medicine? J Psychopharmacol. (2021). doi: 10.1177/02698811211008567

270. Wolff M, Evens R, Mertens LJ, Koslowski M, Betzler F, Gründer G, et al. Learning to Let Go: A cognitive-behavioral model of how psychedelic therapy promotes acceptance. Front Psychiatry. (2020) 11:5. doi: $10.3389 /$ fpsyt.2020.00005

271. Mackewn J. Developing Gestalt Counseling. Newbury Park: Sage (1997).

272. Gabbard GO, Litowitz BE, Williams P. Textbook of Psychoanalysis. Washington: American Psychiatric Pub. (2012).

273. Wade DT, Halligan PW. The Biopsychosocial Model of Illness: A Model Whose Time Has Come. London, England: SAGE Publications Sage UK (2017).

Conflict of Interest: The authors declare that the research was conducted in the absence of any commercial or financial relationships that could be construed as a potential conflict of interest.

Copyright (C) 2021 Kočárová, Horáček and Carhart-Harris. This is an open-access article distributed under the terms of the Creative Commons Attribution License (CC $B Y)$. The use, distribution or reproduction in other forums is permitted, provided the original author(s) and the copyright owner(s) are credited and that the original publication in this journal is cited, in accordance with accepted academic practice. No use, distribution or reproduction is permitted which does not comply with these terms. 